Article

\title{
Analysis of Sustainable Materials for Radiative Cooling Potential of Building Surfaces
}

\author{
Roxana Family * (iD) and M. Pinar Mengüç * \\ Center for Energy, Environment and Economy (CEEE) and Department of Mechanical Engineering, Ozyegin \\ University, 34794 Çekmekoy, Istanbul, Turkey \\ * Correspondence: roxana.family@ozu.edu.tr (R.F.); pinar.menguc@ozyegin.edu.tr (M.P.M.); \\ Tel.: +90-216-564-9327 (M.P.M.)
}

Received: 13 July 2018; Accepted: 10 August 2018; Published: 28 August 2018

\begin{abstract}
The main goal of this paper is to explore the radiative cooling and solar heating potential of several materials for the built environment, based on their spectrally-selective properties. A material for solar heating, should have high spectral emissivity/absorptivity in the solar radiation band (within the wavelength range of $0.2-2 \mu \mathrm{m}$ ), and low emissivity/absorptivity at longer wavelengths. Radiative cooling applications require high spectral emissivity/absorptivity, within the atmospheric window band $(8-13 \mu \mathrm{m})$, and a low emissivity/absorptivity in other bands. UV-Vis spectrophotometer and FTIR spectroscopy, are used to measure, the spectral absorption/emission spectra of six different types of materials. To evaluate the radiative cooling potential of the samples, the power of cooling is calculated. Heat transfer through most materials is not just a surface phenomenon, but it also needs a volumetric analysis. Therefore, a coupled radiation and conduction heat transfer analysis is used. Results are discussed for the selection of the best materials, for different applications on building surfaces.
\end{abstract}

Keywords: spectrally-selective surfaces; radiative cooling; coupled radiation-conduction heat transfer; sustainable materials; roofs; built environment

\section{Introduction}

Buildings are responsible for about $35-40 \%$ of all energy used globally. The way the building surfaces emit and absorb radiative energy during daytime or nighttime, determines the energy loss or gain by them, which is correlated to the energy they use for heating or cooling purposes. It is often desired to tailor the radiative properties of surfaces, to change their natural ability to absorb, emit, or reflect radiative energy. The Earth's atmosphere is almost transparent to the emitted radiation from an object, between the wavelengths of $8-13 \mu \mathrm{m}$. This means that almost all radiative energy within this band can be easily lost to the sky and helps the objects cool off. This wavelength interval is called the "atmospheric window". The key to obtain radiative cooling, is to create an imbalance between the absorbed radiation from the environment and the heat radiated outwards through the atmospheric window. In situations where a surface is to be kept cool while subjected to the Sun, it is necessary to have the maximum reflection of solar energy within the wavelength range of $0.2-2.0 \mu \mathrm{m}$, where incoming radiative energy is maximum, and to have maximum radiative emission from the surface in the $8-13 \mu \mathrm{m}$ wavelength spectrum [1].

If a surface has high absorptivity within the visible and ultraviolet spectrum (i.e., the wavelength range of $0.2-2.0 \mu \mathrm{m}$ ), it can absorb most solar radiation similar to a blackbody. The Planck equation, describes the spectral-energy distribution of radiation emitted by a blackbody, which is a hypothetical body that absorbs all radiant energy falling on to it. A blackbody is also the maximum emitter, and its equilibrium temperature is determined by carrying out the radiative energy balance on it. If a surface 
is in a vacuum, it may not have any energy transfer by conduction or convection; then the equilibrium temperature is determined by pure radiative transfer analysis. Otherwise, both conduction and convective heat transfer gains and losses should be accounted for in the calculations [1].

In order to attain an equilibrium temperature below the ambient during daytime radiative cooling, it is important to reflect more than $88 \%$ in-coming solar radiation [2]. This so-called spectrally-selective reflection, can be achieved using special coatings. However, covering an object with a strong solar reflector notably alters its color, which might not be favorable for visual reasons [3]. Other alternatives include polished metals, which may be used for some applications as a highly reflective coating; yet, they usually have high reflectivity at the atmospheric window as well. Copper oxide and copper sulfide metal films, are examples used for solar thermal applications [4].

For thermal control in outer space, various spectrally-selective surfaces have also been used. Among them, OSR or the optical solar reflector, is a mirror composed of a glass layer silvered on the back side. The glass is transparent in the short wavelength region and allows the silver substrate to reflect incident radiation in this spectral region [1]. In low thrust radiation-cooled rockets or space crafts, the most common material used is a niobium alloy (C-103) with a fused silica coating (R-512A or R-512E) for oxidation protection. A new class of oxidation-resistant and high-temperature materials have also been developed for radiation-cooled rockets. Rhenium coated with iridium is one of the most common of these high-temperature materials. Additionally, different material systems have been studied, such as hafnium carbide/tantalum carbide matrix composites and ceramic oxide-coated iridium/rhenium chambers [5].

Paints are also important for radiative cooling applications. Paints are the mixture of pigments and resin, and pigments are metal oxides and semiconductors [1]. Most paints emit strongly at the longer wavelengths, that is at infrared spectrum beyond $2.0 \mu \mathrm{m}$, and they also strongly reflect the incident solar radiation at shorter wavelengths [1]. Titanium dioxide based white paint, usually used as an external solar-selective coating, is preferable among other paints [6], whilst, metalized Teflon, aluminized Kapton, and some light colored paints darken over a long period of time and degrades their performance [7].

Absorptivity, emissivity, and reflectivity are material properties of a surface. Therefore, changing the surface characteristics of a material alters its reflectivity, absorptivity, and emissivity. The modification of a surface, might result in increased absorptivity or emissivity due to reduced reflectivity. A surface coating, for example, may transfer more long-wavelength radiation (infrared, IR) into a low emissivity material, or it might decrease its absorptivity and emissivity by increasing the overall reflectivity, and by prohibiting a material from radiating infrared energy. This is the reason that surface modifiers, such as paint and shiny metal cladding, decrease or increase a material's apparent emissivity [8].

Gonome et al. [9] compared the $\mathrm{CuO}$ pigment with Titanium dioxide $\left(\mathrm{WO}_{2}\right)$ white pigments. Their results showed that although the $\mathrm{CuO}$ coating displays a dark, black-color, the performance of $\mathrm{CuO}$ pigment was much higher than that of Titanium dioxide white pigment. Another class of selective emitters is based on rare earth metals, due to their high absorption in the infrared spectrum [10-12]. These metals are rarely considered in practical applications because of they are not widely available; however, they have found some recent use as composites where they are mixed with other materials, such as titania or other ceramics. The problem with these rare earth composites, is that at higher temperatures, grey-body like emission starts to dominate the emission.

Another way to achieve spectrally-selective surface characteristics is based on using regular micro-roughness (a "grating") on a surface. The roughness dimension in such structures, should be comparable to the size of the wavelength of interest [13-15]. Using electromagnetic scattering theory, such wavelength-selective behavior can be determined, which has been experimentally verified [16,17]. In applications that need absorption peaks at different wavelength bands, nanoscale structures and nano-sized metal particles embedded in semiconductor matrix or insulators have been preferred [11]. However, these nano- or micro-structured materials are expensive and their fabrication process is 
time-consuming. Instead, it is desirable to find natural materials that can be used as spectrally-selective absorbers and reflectors in many applications, from buildings to any other devices. These so-called sustainable materials can be produced in high volumes, without disrupting the established steady-state equilibrium of the environment [18]. In the present work, we studied several of these materials to determine their potential for radiative cooling of building walls and roofs.

Conduction and radiation are the two main heat transfer modes that can be considered at the roofs and walls of the built environment. Although thermal radiation can be treated independently, in many cases it needs to be coupled with heat conduction. Radiation is a surface phenomenon for optically thick solids and liquids, yet for porous media, it is a volumetric phenomenon. As such, a coupled conduction and radiation problem needs to be solved, which allows the calculation of the temperature profile within a material [19].

The radiation energy within a medium is tracked by solving the radiative transfer equation (RTE). Furthermore, the conservation of energy or the first law of thermodynamics must be satisfied, resulting in the overall energy equation (EE). The EE and RTE are coupled in a participating medium. The divergence of the radiative flux, enters as the sink or the source term in the EE, so long as the temperature that is obtained by solving the EE at any point, influences local emission and radiative properties affecting the solution of the RTE [1,20].

As mentioned before, our objective in this study is to evaluate radiative cooling at the roofs and walls of buildings, by using inexpensive sustainable materials which have not been used upto now. In Figure 1, a schematic for building-related radiative cooling applications is presented; the primary goal of the present study is highlighted by bold lines.

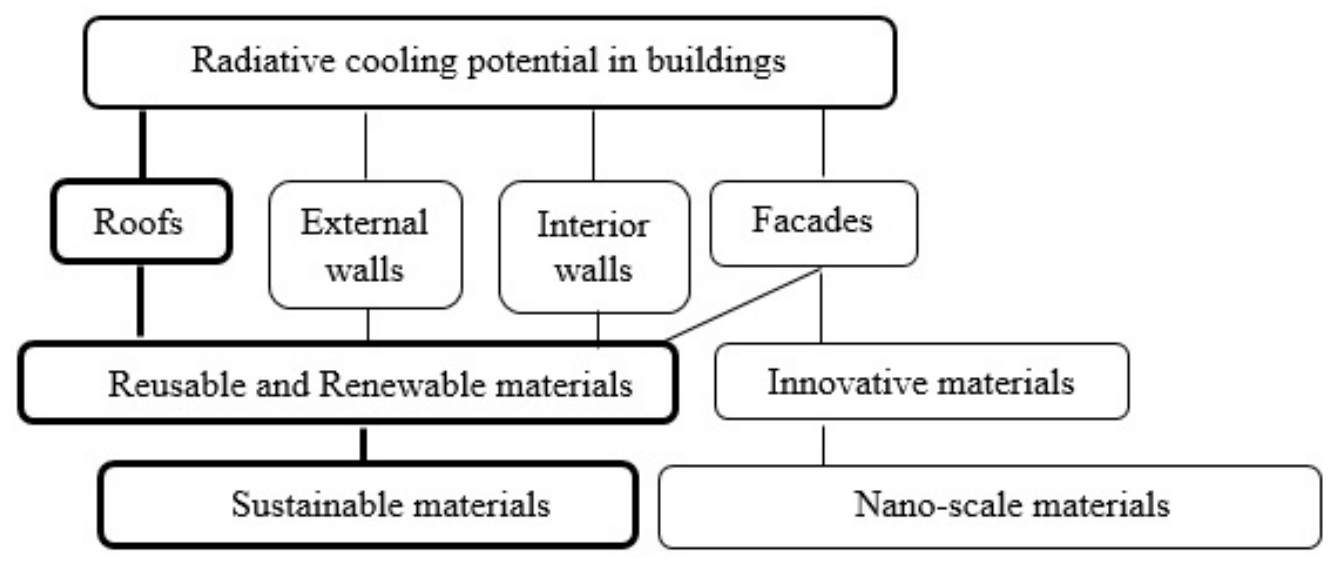

Figure 1. A schematic to show different materials, which can be used for radiative cooling applications in the built environment.

\section{Theoretical Analysis}

First, we provide a simple analysis of heat balance for buildings surfaces. Temperature is assumed constant within the medium, and we consider only the radiative energy balance on a surface. This is called the 'power-of-cooling' analysis. The schematic for the system considered, is shown in Figure 2. 


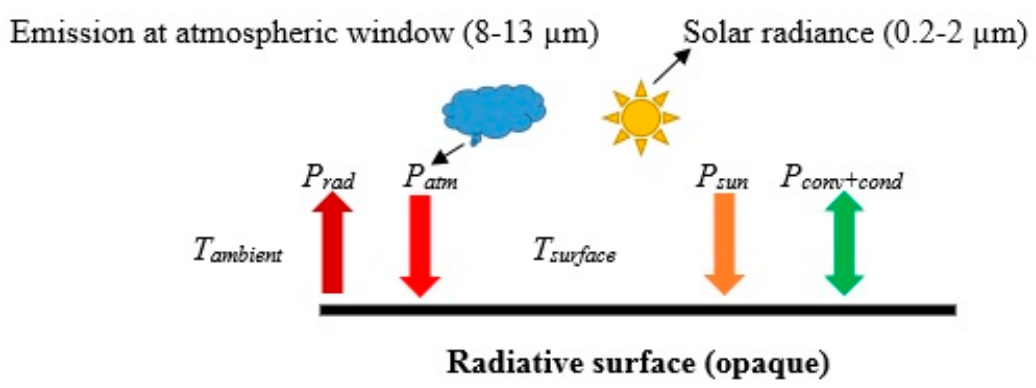

Figure 2. Schematic of radiative cooling, based on radiative energy balance on an opaque surface.

We consider the temperature, $T_{S}$, of an opaque surface as constant. It is assumed to have directional and spectral emissivity $\varepsilon(\lambda, \Omega)$, where $\lambda$ is the wavelength, and $\Omega$ is the solid angle. The surface is subjected to solar irradiance and atmospheric irradiance and is exposed to a clear sky corresponding to an ambient temperature $T_{a m b} . P_{n e t}(T)$ is the net cooling power of the surface per unit area of the surface, which is defined as:

$$
\begin{gathered}
P_{\text {net }}(T)=P_{\text {out }}-P_{\text {in }} \\
P_{\text {out }}=P_{\text {rad }}(T)=Q_{\text {emitted }}\left(T_{s}\right) \\
P_{\text {rad }}(T)=\int d \Omega \cos \theta \int_{0}^{\infty} d \lambda I_{B B}(T, \lambda) \varepsilon(\lambda, \Omega)
\end{gathered}
$$

The radiated energy by the surface per unit area is integrated over all angles,

$$
\int d \Omega=\int_{0}^{\frac{\pi}{2}} d \theta \sin \theta \int_{0}^{2 \pi} d \phi
$$

which provides the angular integral over a hemisphere. The spectral intensity of the Planck blackbody radiation at temperature $T$ is given as [1]

$$
I_{B B}(T, \lambda)=\left(2 h c^{2} / \lambda^{5}\right) /\left[e^{h c /\left(\lambda K_{B} T\right)}-1\right]
$$

which yields,

$$
\begin{gathered}
P_{\text {in }}=P_{\text {atm }}\left(T_{a m b}\right)+P_{\text {Sun }}+P_{\text {conv }} \\
P_{a t m}\left(T_{a m b}\right)=\int d \Omega \cos \theta \int_{0}^{\infty} d \lambda I_{B B}\left(T_{a m b}, \lambda\right) \varepsilon(\lambda, \Omega) \varepsilon_{a t m}(\lambda, \Omega)
\end{gathered}
$$

is the absorbed power per unit area emerging from the atmosphere, and

$$
P_{\text {Sun }}=\int_{0}^{\infty} d \lambda \varepsilon(\lambda, 0) I_{A M 1.5}(\lambda)
$$

is the incident solar power absorbed by the surface per unit area. In writing Equations (7) and (8), Kirchhoff's law $\varepsilon(\lambda, 0)=\alpha(\lambda, 0)$ was used for the zenith angle of zero. The direction-dependent emissivity of the atmosphere is given by

$$
\varepsilon_{a t m}(\lambda, \Omega)=1-t(\lambda)^{1 / \cos \theta}
$$

where $t(\lambda)$ is the atmospheric transmittance in the zenith direction [21]. $k_{B}, \lambda, h$, and $c$, are the Boltzmann constant, wavelength, the Planck constant, and the speed of light, respectively. In Equation (8), the solar 
illumination is represented by AM1.5 Global Tilt spectrum with an irradiance of $964 \mathrm{~W} / \mathrm{m}^{2}$, which represents the average solar conditions of the continental U.S. [3], and is similar to that for Turkey. We assume that the surface is facing the sun; therefore, $P_{\text {sun }}$ is not direction dependent. The emissivity of the surface is represented by its value at the zenith direction $\theta=0$ and is equivalent to $\varepsilon(\lambda, 0)$.

$$
P_{\text {conv }}\left(T, T_{a m b}\right)=A h_{c}\left(T_{a m b}-T\right)
$$

The lost power by convection heat transfer is neglected here, for the sake of simplicity.

Coupled Heat Conduction and Radiation Transfer with Temperature Profile in One-Dimensional Non-Gray Media

Next, we consider a thick semi-transparent structure (Figure 3), where both the volumetric radiation and conduction heat transfer are accounted for in the analysis. Absorption and emission of radiation are considered from both sides of the surface. In this work, we applied $\mathrm{P}_{1}$ approximation for the solution of radiative transfer equation $[1,22]$.

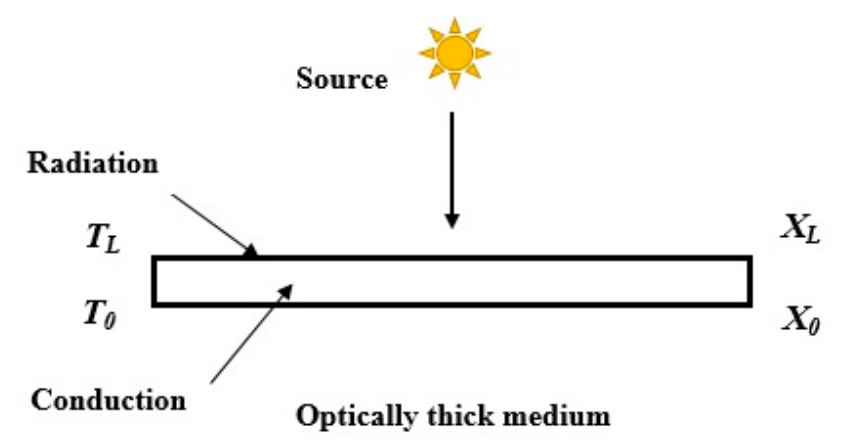

Figure 3. Schematic of an optically thick medium, where both radiation and conduction transfer are considered.

The conservation of energy equation is written based on one dimensional steady-state case and the energy balance can be expressed in a narrow strip. The divergence of total heat flux is expressed for coupled heat conduction and radiation as [1,23-25].

$$
\frac{d q_{t o t}}{d x}=\frac{d q_{c o n}}{d x}+\frac{d q_{r a d}}{d x}=0
$$

where $q_{\text {rad }}$ and $q_{c o n}$ are the radiative and conductive heat fluxes, respectively, and $k$ is the thermal conductivity. The conductive heat flux in the medium is given by the Fourier law [23]

$$
\frac{d q_{c o n}}{d x}=-k \frac{d^{2} T}{d x^{2}}
$$

The divergence of the spectral radiative heat flux based on stepwise spectrally gray box model, and is written as

$$
\frac{d q_{r a d}}{d x}=\sum_{j=1}^{N_{B}+1} \kappa_{j}\left(4 E_{b j}-G_{j}\right)
$$

$\kappa_{\lambda}$ and $G_{j}$ are the absorption coefficient and the incident radiation in $j$-th spectral box (wavelength interval), and $N_{B}$ is the number of gray boxes. $G_{j}$ would be defined

$$
G_{j}=\int_{\lambda_{j, l}}^{\lambda_{j, u}} G_{\lambda} d \lambda
$$


$\lambda_{j, l}$ and $\lambda_{j, u}$ are the lower and upper boundaries of the $j$-th gray box. In this study, we assumed a homogeneous medium without any particles, therefore there is no scattering, and the absorption coefficient is equal to the extinction coefficient. Substitution of Equations (12) and (13) into the Equation (11) yields Equation (15):

$$
k \frac{d^{2} T}{d x^{2}}=\sum_{j=1}^{N_{B}+1} \kappa_{j}\left(4 E_{b j}-G_{\lambda}\right) d \lambda
$$

The parameter $N_{B}+1$ corresponds to the part of the spectrum which is outside of the defined spectral boxes, or so-called windows. The incident radiation $G_{j}$ can be determined using the $P_{1}$ approximation for non-scattering medium. As mentioned above, we assume non-gray, homogeneous non-scattering, and a one-dimensional medium which is confined between isothermal boundaries. Using such boundary conditions, which are $T(0)=T_{0}$ and $T(L)=T_{L}$ (Figure 4), the following governing equations need to be solved [22]

$$
\frac{d^{2} G_{\lambda}}{d x^{2}}=-3 \kappa_{\lambda}^{2}\left(4 E_{b \lambda}-G_{\lambda}\right)
$$

with the boundary conditions

$$
\begin{aligned}
& \left.\frac{d G}{d x}\right|_{x=0}+\frac{3}{2} \frac{\varepsilon_{0 \lambda}}{2-\varepsilon_{0 \lambda}} \kappa_{\lambda}\left[4 E_{b \lambda}(0)-G_{\lambda}(0)\right]=0 \\
& \left.\frac{d G}{d x}\right|_{x=L}-\frac{3}{2} \frac{\varepsilon_{L \lambda}}{2-\varepsilon_{L \lambda}} \kappa_{\lambda}\left[4 E_{b \lambda}(L)-G(L)\right]=0
\end{aligned}
$$

Equations (15) and (16) can be written in the matrix form for the solution, as explained by Mazumder [20].

If we use a spectral extinction coefficient, we should choose one of the non-gray methods, such as stepwise gray box models, narrow band models, wideband models, weighted-sum-ofgray-gases-models, and recently, narrowband $k$ distributions or full spectrum $j$ distributions. As explained in References $[1,19,20]$, some of these methods are extremely time-consuming for ordinary engineering calculations; so we selected the gray box model, which is simple and effective for non-gray calculations.

\section{Experimental Studies}

\subsection{Materials}

The concept of passive radiative cooling in buildings, returns to Roman times and recent cool-roof treatments in subtropical climates. Instead of different oxide and non-oxide ceramics that can be used for these purposes, inexpensive, readily available materials may be preferable to construct roof panels for attaining night time and day time passive cooling in tropical locations [26]. We consider sustainable, readily-available and relatively inexpensive materials (such as expanded polystyrene, perlite pumice composite, and its painted and planted types), for possible radiative cooling in buildings. In the first step, we used these materials as insulating materials, as reported in our recent papers [27,28]. The materials which we used in this paper, are listed in Table 1.

Sustainable materials, are those materials which provide social, environmental, and economic benefits whilst protecting public health and the environment over their whole life cycle, i.e., from their extraction of as a raw material until their final disposal; and sustainable building materials are typically certified to be sustainably managed. They are non-toxic, recycled materials, reusable and renewable, so they have an environmental benefit $[29,30]$.

Each of these materials is briefly explained below:

XPS: Extruded polystyrene foam contains closed cells, causes meliorate higher stiffness and surface roughness, and has low thermal conductivity. Density range is about $28-45 \mathrm{~kg} / \mathrm{m}^{3}$. It absorbs 
only minimum quantities of moisture, and is resilient and resistant to aging and rotting. Its thermal conductivity varies between 0.029 to $0.039 \mathrm{~W} /(\mathrm{m} \cdot \mathrm{K})$ with an average value of $\sim 0.035 \mathrm{~W} /(\mathrm{m} \cdot \mathrm{K})$ based on its strength/density. Water vapor diffusion resistance $(\mu)$ of XPS is around 80-250; therefore, XPS is suitable for wetter environments.

Extruded XPS, is in the form of continuous foam billets. Polystyrene is melted inside of the extruder, and by adding carbon dioxide $\left(\mathrm{CO}_{2}\right)$ or sometimes partially halogenated fluorochlorohydrocarbon as a foaming agent, it extrudes through a nozzle, and finally, thicknesses between 20 and $200 \mathrm{~mm}$ can be produced. While running through a cooling zone, the billet can be cut (by sawing) into panels in a subsequent machine and the edges can be formed. The foam skin stays on the external surfaces of the panels. In the case of using for "insulation under plaster", the foam skin can be removed. Finally, the panels are aged to admit dimensional consistency [31,32].

Table 1. List of the materials.

\begin{tabular}{l}
\hline \multicolumn{1}{c}{ Name } \\
\hline XPS = Extruded Polystyrene Foam \\
Consists of closed cells, which improved higher stiffness and surface roughness and \\
reduced thermal conductivity [27]. \\
\hline $\begin{array}{l}\text { Perlite Pumice Cement Composite (PPC) } \\
\text { They are derived from volcanic rock and might be applicated in a variety of soil mixes [28]. }\end{array}$ \\
\hline
\end{tabular}

White Painted PPC

The PPC sample was painted with white paint in the laboratory.

Black Membrane

The Black membrane is EPDM (Ethylene propylene diene monomer (M-class) rubber),

which is explained in the text $[33,34]$.

Red Membrane

The Red membrane is the red shingle, which is explained in the text $[35,36]$.
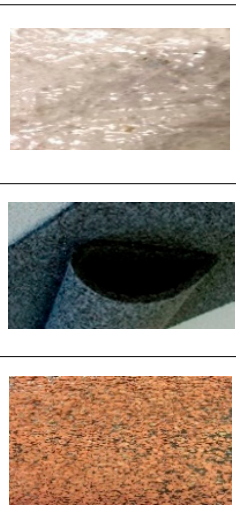

Plant or moss

Simple grass gathered from typical green-roofs at the University campus.

Perlite pumice composite (PPC): Perlite, which has the potential to be utilized as a raw material in geopolymerization technology, is an amorphous aluminosilicate volcanic glass. It has $2-5 \%$ combined water. If heated to temperatures between $760^{\circ} \mathrm{C}$ and $1150{ }^{\circ} \mathrm{C}$, it expands 10 to 30 times of its original volume, depending on the raw material mixture [37-39].

Pumice can be considered as a sustainable building material [40]. Pumice with a sponge-like structure is a lightweight volcanic aluminum silicate, which is formed by the expansion of gases when molten lava rapidly cools. It has a low bulk density in the range of $480-960 \mathrm{~kg} / \mathrm{m}^{3}$ and has low thermal conductivity, low sound transmission characteristics, and high strength-to-weight ratio. These properties make it favorable as an additive for lightweight aggregate, bricks, and blocks and aggregate for plaster and concrete [41]. In this study, we used perlite pumice composite powder (PPC), which is shown in Figure 4. We mixed it with enough water like a slurry and poured it in two molds for making our samples. After drying, we painted the upper surface of one of them with white paint for our experiments. 


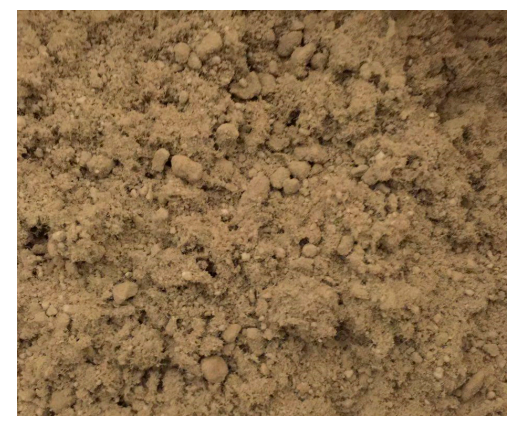

Figure 4. Perlite Pumice Composite powder (PPC) camera image.

Black membrane or EPDM: EPDM rubber (ethylene propylene diene monomer (M-class) rubber), is a kind of synthetic rubber and an elastomer with several potential applications. EPDM is an extremely durable membrane that is widely used in low-slope buildings. Its two primary ingredients, propylene and ethylene are derived from natural gas and oil. EPDM exists in both white and black colors, and is sold in a wide variety of widths, ranging from $2.2-15.2 \mathrm{~m}$, and in two different thicknesses of 1.1 and $1.5 \mathrm{~mm}$. EPDM may be installed either fully adhered, ballasted, or mechanically attached, sealed with liquid adhesives or specially formulated tape with the seams of the roofing system [34].

Red membrane: Red membrane is a type of wall or roof element that uses asphalt for waterproofing. There are two dominant base materials in forming asphalt shingles. First one, has a fiberglass base and second, a formerly-living organic base. Both types are produced in a similar manner, with asphalt or modified-asphalt applied to one or both sides of the asphalt-saturated base, covered with quartz, ceramic granules, stone or vitrified brick and the back side treated with mica, sand, or talc to inhibit the shingles from sticking to each other before usage. The top surface granules, provide some physical protection of the asphalt and give the shingles their color by blocking ultraviolet light. To avoid shingles from being separated by high winds, self-sealing strips are used as adhesion on shingles. Shingles are commonly manufactured from limestone, fly-ash-modified resins, or polymer-modified bitumen element. SBS or a styrene-butadiene-styrene, sometimes called rubberized or modified asphalt, is sometimes added to the asphalt mixture as an additive to create shingles more resistant to thermal cracking, as well as more resistant to damage from hail strikes $[37,38]$. In this work, we used a red version and called it red membrane.

Plant or Moss: For modeling a green roof, we used moss from the roof-tops of the buildings at the campus of Ozyegin University. A moss is a plant which is produced of spores and is flowerless, with the spores produced in small capsules. They typically grow in dense green mats or clumps, frequently in shady or damp locations [42]. The image of the sample and its corresponding optical microscope microstructure, are shown in Figures 5 and 6.

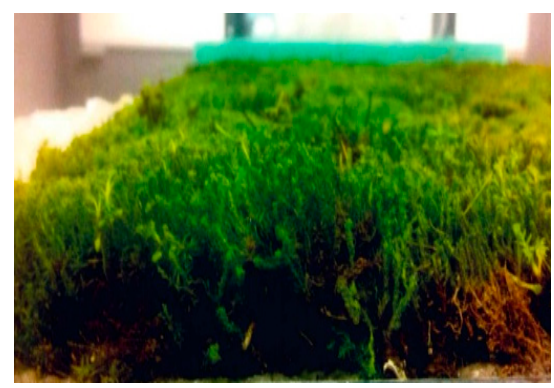

Figure 5. Moss sample camera image. 


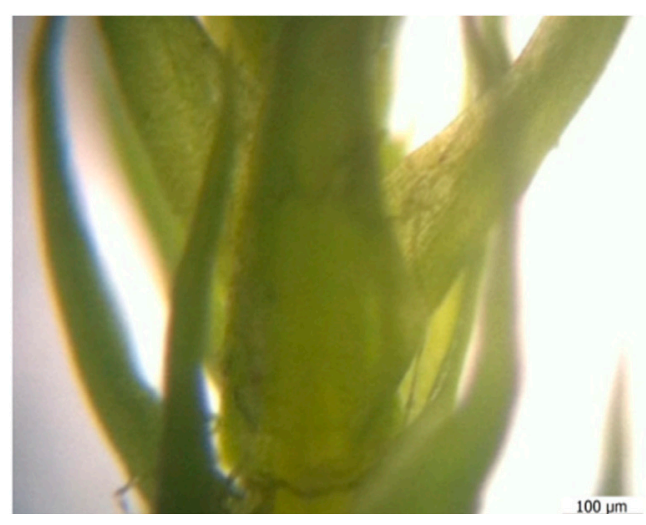

Figure 6. Structure of moss under optical microscope.

\subsection{Spectral Measurement and Analysis}

For a detailed discussion of radiative cooling, we needed to know the spectral properties of the samples. In this regard, all six samples were analyzed using a UV-Visible spectrophotometer and Fourier Transform Infra-Red (FTIR) spectroscopy. The UV-Visible spectrophotometer, uses light in the visible and at near-UV and near-infrared wavelengths [43]. FTIR spectroscopy is a technique which is used to obtain the infrared spectrum of absorption or emission of a solid, liquid, or gas. The FTIR spectrometer, simultaneously collects high spectral resolution data over a wide spectral range, from 2 to $20 \mu \mathrm{m}$, or more [44,45].

All FTIR spectroscopy data were recorded as direct (specular) absorbance or transmittance. Diffuse absorbance and transmittance spectroscopy measurements in the UV-Visible near IR region, were carried out on a Nicolet iS10 FTIR Spectrometer. Spectra were recorded at room temperature, between 4000 and $400 \mathrm{~cm}^{-1}$ (wavenumber). In infrared spectroscopy, IR radiation is incident on a sample; then some of the infrared radiation passes through (transmitted) and some of it is absorbed by the sample. The resulting spectrum represents the transmission and absorption of a sample [46-48].

\section{Results and Discussion}

\subsection{Experimental Results}

We first provide the experimental results as measured from the UV-Visible spectrophotometer and FTIR spectroscopy, which correspond to the solar window of $0.2-2 \mu \mathrm{m}$ and the atmospheric window of 8-13 $\mu \mathrm{m}$ wavelength intervals. A system with high emissivity in both solar radiation and atmospheric window bands can act as a solar heating system during daytime, and also a radiative cooling system at night time $[49,50]$. It is effectively an ideal surface for this application; its expected spectrum is shown in Figure 7.

Solar collectors have high emissivity in the solar radiation band and low emissivity in other bands. The solar radiation band, within the $0.2-2 \mu \mathrm{m}$ wavelength range, can be used for determining the best solar collection ability, whereas, $8-13 \mu \mathrm{m}$ is the atmospheric window band, which is significant for selecting the best radiative emitters or radiative coolers. By using the UV-Visible spectrophotometer in this study (Section 4.1.1 in the following), the best material with potential of being a solar collector was selected, whereas by using the FTIR spectrometer, the best candidates for radiative cooling application were selected. 


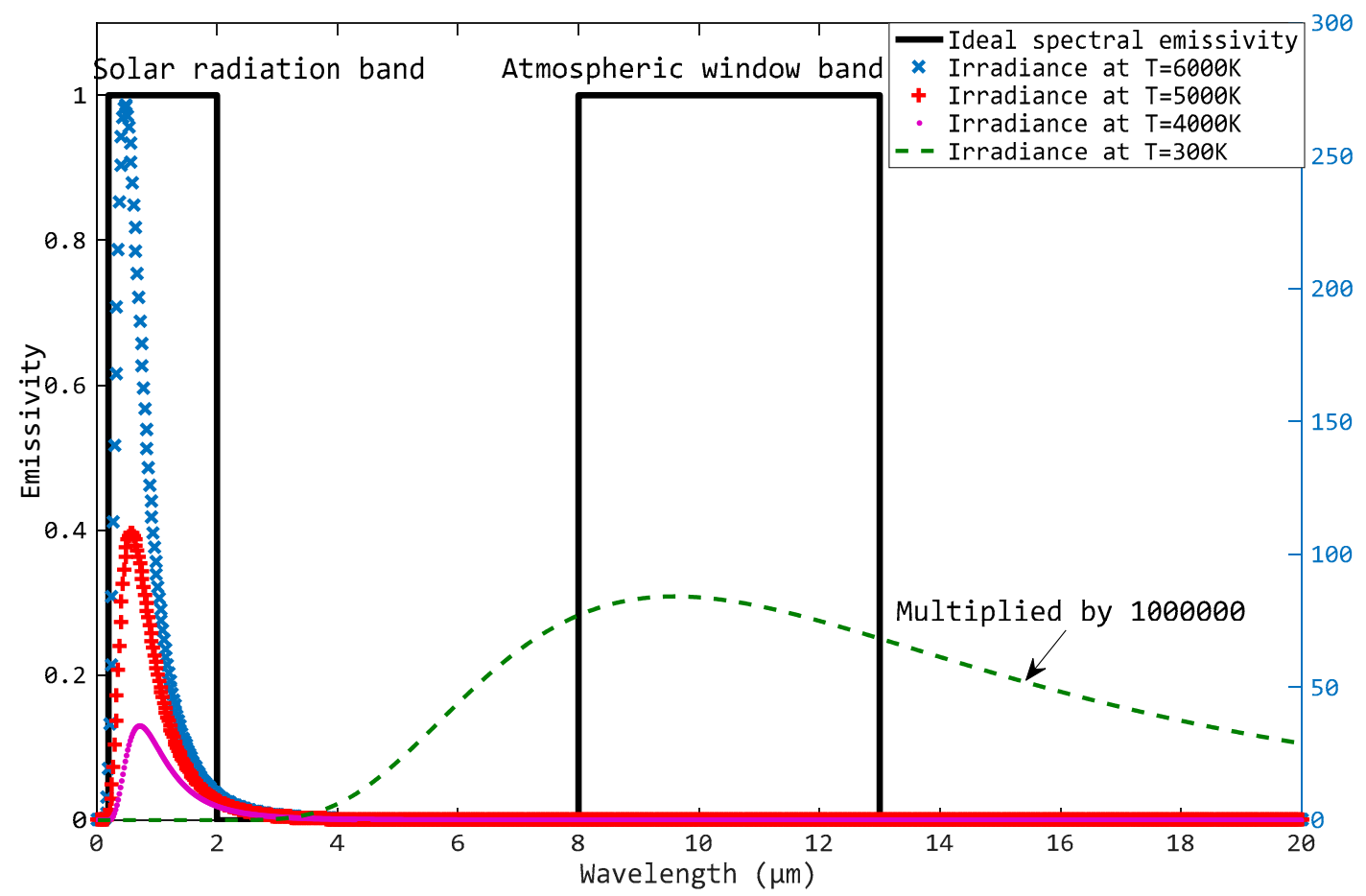

Figure 7. Ideal surface spectral emissivity, for solar heating and radiative cooling applications. The rectangular boxes show the desired spectral bands for the ideal case. Irradiance for $\mathrm{T}=300 \mathrm{~K}$ is drawn after multiplying by $10^{6}$.

\subsubsection{UV-Visible Spectra Measurements}

UV-Visible absorption spectroscopy, is the measurement of the attenuation of a beam of light after it passes through a sample, or after it reflects from a sample surface. Absorption measurements might be at a single wavelength or over a spectral range [51]. To analyze the solar to thermal conversion efficiency of the materials and to evaluate the behavior of the samples within solar radiation band, the UV-Visible spectra of the samples were measured. They are depicted in Figure 8, where the UV-Visible spectrum of each sample is unique.

Because the samples considered were opaque; their spectral transmissivity was zero. We know $\alpha_{\lambda}+\tau_{\lambda}+\rho_{\lambda}=1$, and therefore, $\alpha_{\lambda}=1-\rho_{\lambda}$. Based on Kirchhoff's Law, $\alpha_{\lambda}=\varepsilon_{\lambda}$. Hence, the results provided below for lower reflectivity, correspond to higher emissivity.

The results in Figure 8, show the black membrane is the only sample that has low reflectivity and high emissivity in the solar radiation band. Black membrane showed no reflection peak in UV light range, so based on the mentioned formulations above, it showed high absorption peak at UV. It can be noted from its spectra, that the absorption characteristic of the black membrane has a broader absorption wavelength compared to the other samples. If the samples were evaluated for a solar heating model or solar collector, black membrane would be the best candidate to be used. 


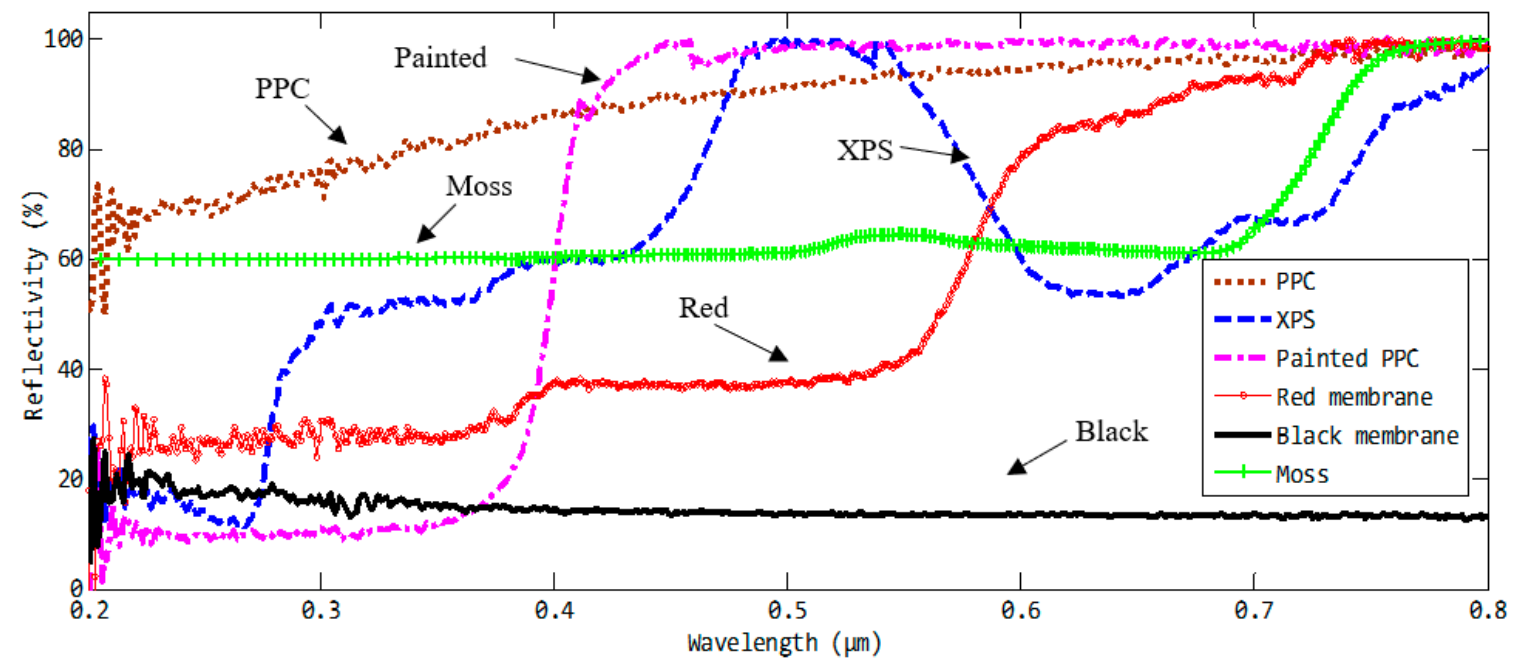

Figure 8. Spectral reflectivity of different samples at near-infrared, $0.2-0.8 \mu \mathrm{m}$ wavelength range. Measurements were made using a Shimadzu 3150 UV-Visible-NIR Spectrophotometer (Performed at Sabanci University, Istanbul, Turkey).

\subsubsection{FTIR Spectroscopy Experiments}

In FTIR spectroscopy, IR radiation is passed through a sample, which is partially absorbed or transmitted. The resulting spectrum represents the absorption and transmission of a sample [52,53]. To evaluate the spectral characteristics of different samples in the atmospheric window, we used an FTIR spectrometer and measured their spectral absorption profile. Based on Kirchhoff's law, the spectral emissivity is the same as the spectral absorptivity $\varepsilon(\lambda, 0)=\alpha(\lambda, 0)$; for that reason, we refer the results shown in Figure 9 as the spectral emissivity.

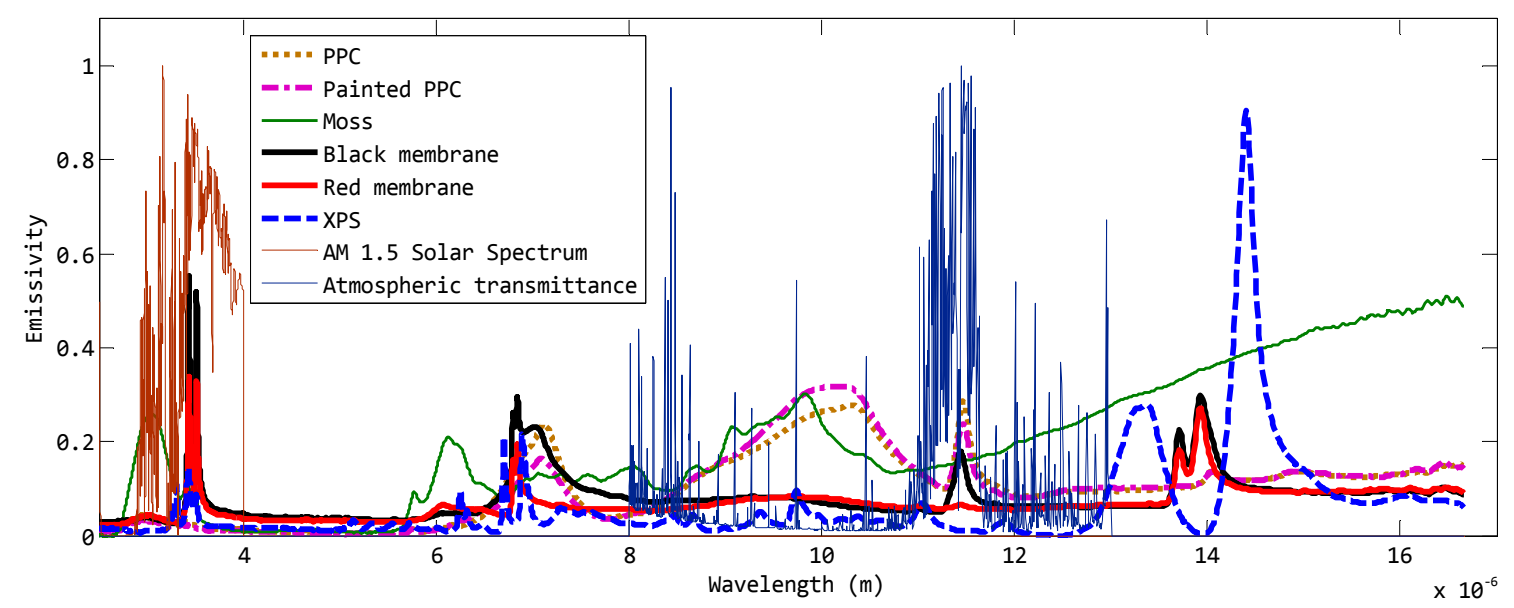

Figure 9. Spectral emissivity of the samples measured by Thermo-Nicolet iS10 FTIR spectrometer. (Performed at Sabanci University, Istanbul, Turkey).

We note from the data given in Figure 9 that moss, PPC, and Painted PPC have high spectral emissivity in the atmospheric window range of $8-13 \mu \mathrm{m}$, whereas their spectral emissivity is low within the other bands. This means that they can be good candidates as radiative emitters in the long wavelengths and for radiative cooling applications in daytime. On the other hand, XPS, black membrane, and red membrane had low spectral emissivity in the atmospheric window, so they do not have the potential to be used as a radiative cooler. 


\section{Spectral Absorption Coefficient}

The absorption spectra of the samples in two series, are presented in Figure 10. Absorbance or absorptivity (or emissivity) of the samples were measured by FTIR, as explained in the previous section. In the samples considered, the spectral properties, which are essential for radiative cooling calculations were not available at all. We had to measure the properties in specific experiments, which could be compared against the numerical results for validation. Such results, are depicted in Figures 8 and 9.

The spectral absorption coefficient $\kappa_{\lambda}$ of the samples can be calculated by [1]

$$
\kappa_{\lambda}=\left(2.3 \times A_{\lambda}\right) / t
$$

where $A_{\lambda}$ is the spectral absorbance measured from the experiments and $t$ is the thickness of a sample. This equation is based on a direct relationship between the spectral absorptivity and the spectral absorption coefficient. We note that high spectral absorption in the atmospheric window yields better performance for radiative cooling, as it was obvious in moss, PPC, and Painted PPC samples.

In the following analysis, the spectral absorption coefficient of the samples was plotted by dividing them into two groups. In the first group, PPC, Painted PPC and moss displayed similar behaviors of increase and decrease in the wavelength range of atmospheric window $(8-13 \mu \mathrm{m})$. However, for the moss sample, after $11 \mu \mathrm{m}$ wavelength there was a dramatic increase in the spectral absorption coefficient. A change like that, in the curvature of the absorption coefficient, shows a change in band gap [54]. In the second group of the samples, XPS, black membrane, and red membrane did not show any significant absorption coefficient in the atmospheric window range.
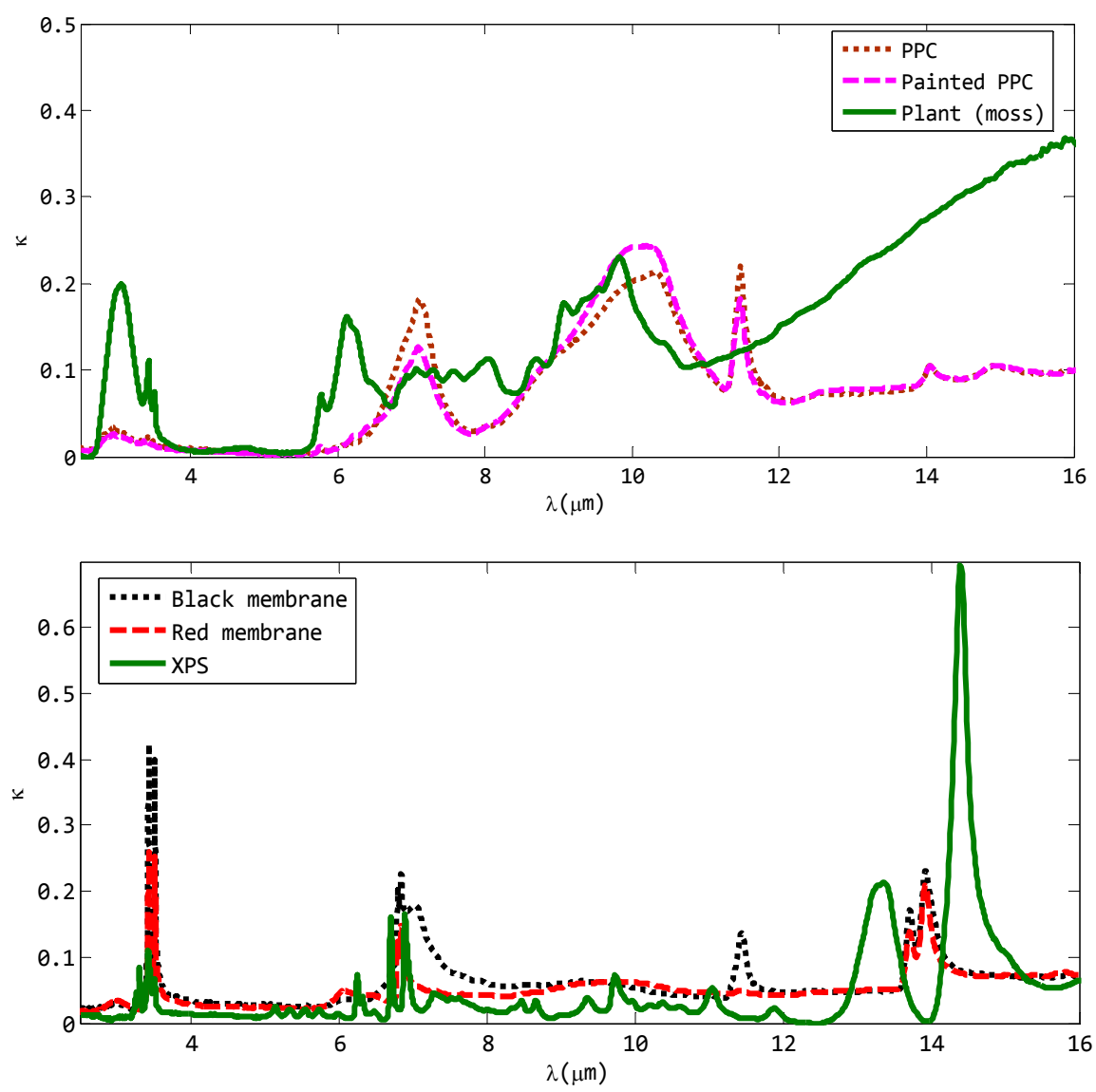

Figure 10. Spectral absorption coefficient (in units of $1 / \mathrm{m}$ ) of roof materials measured by Thermo-Nicolet iS10 FTIR spectrometer (Performed at Sabanci University, Istanbul, Turkey). 
We noted above that high spectral absorption in the atmospheric window is better for radiative cooling. From the results above, it was obvious that moss, PPC, and Painted PPC samples were better candidates for this application.

\section{Band Approximation with Stepwise Gray Box Model}

If a medium is semi-transparent, then radiation penetrates the medium. The ability of the materials to absorb thermal radiation might be expressed by the absorption coefficient [55]. Spectral absorption coefficient of a material, dictates how far spectral radiation penetrates into it, and the absorption coefficient depends on the nature of the material [56,57]. The spectral models for the absorption coefficients (in units of $1 / \mathrm{m}$ ) for six different samples, are presented in Figure 11 . Note that these $\kappa_{\lambda}$ values were determined using the Equation (19) given above.

Three separate spectral intervals (the so-called gray bands) were selected. We considered the solar window, the atmospheric window, and one in between. In Figure 11a, PPC, Painted PPC, and moss results are shown.

In Figure 11b, XPS, black membrane, and red membrane results are presented based on THE stepwise gray box model as explained before.

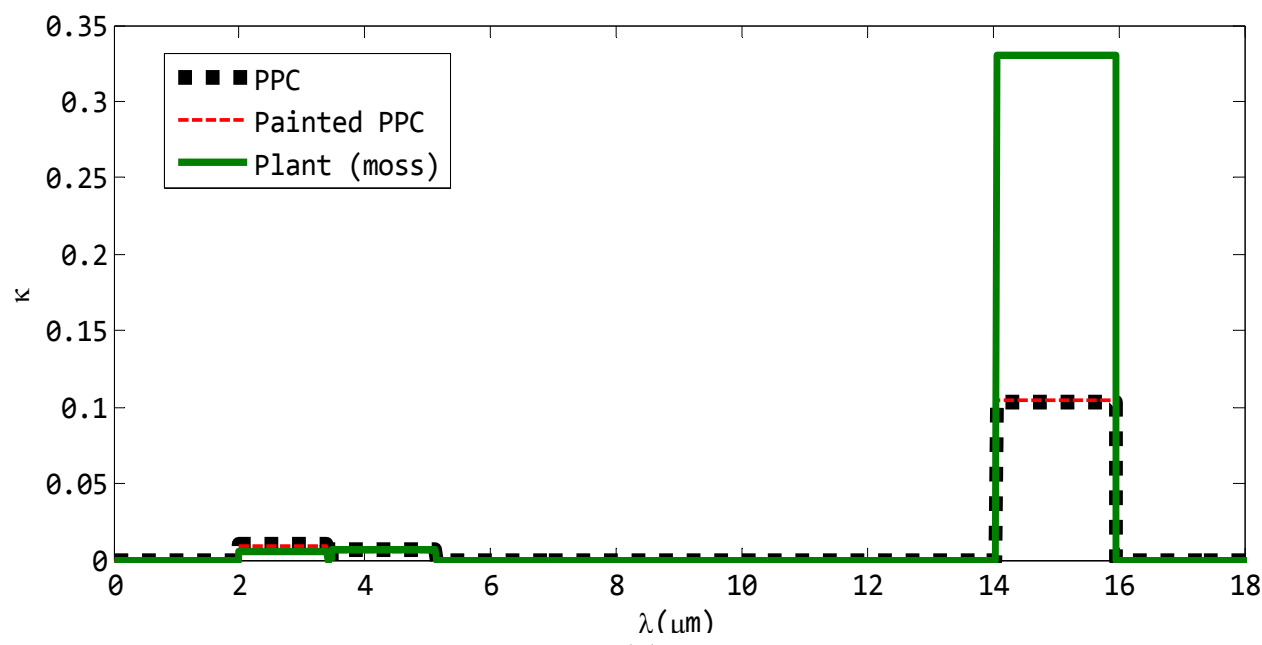

(a)

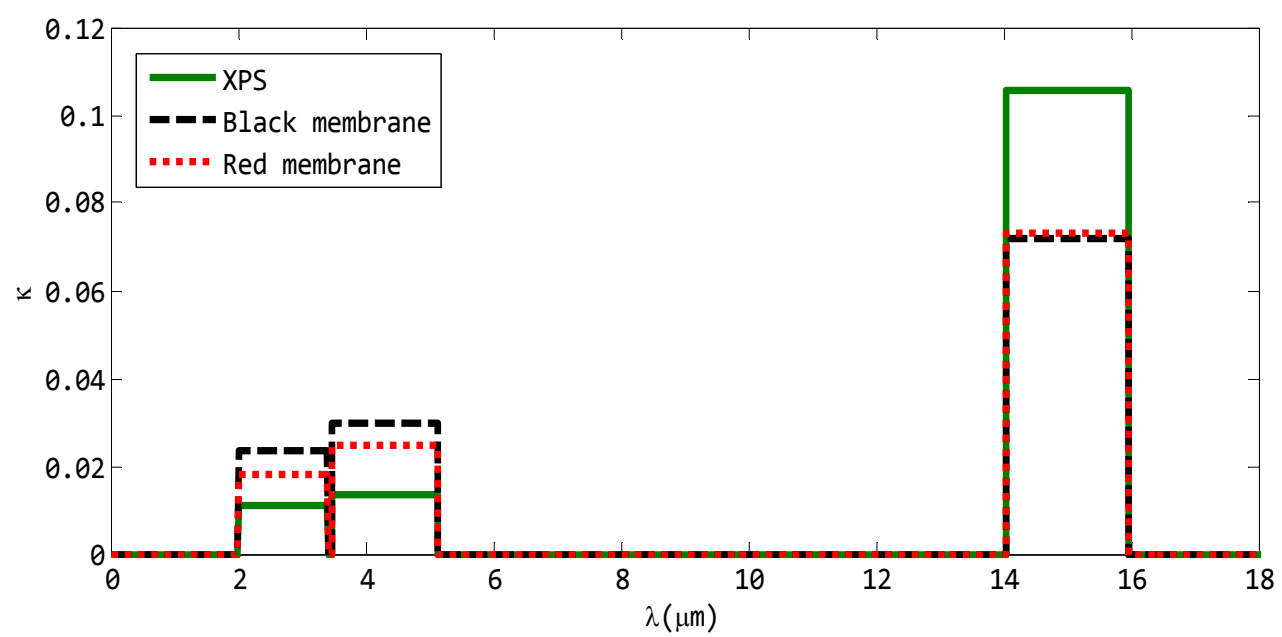

(b)

Figure 11. Box model approximation for the absorption coefficient of six different roof materials; in units of 1/m. (a) PPC, Painted PPC, and Plant (moss); and (b) XPS, Black membrane, and Red membrane. 
Figure 12 represents the spectral absorption coefficient, calculated experimentally and numerically for each of the six samples.
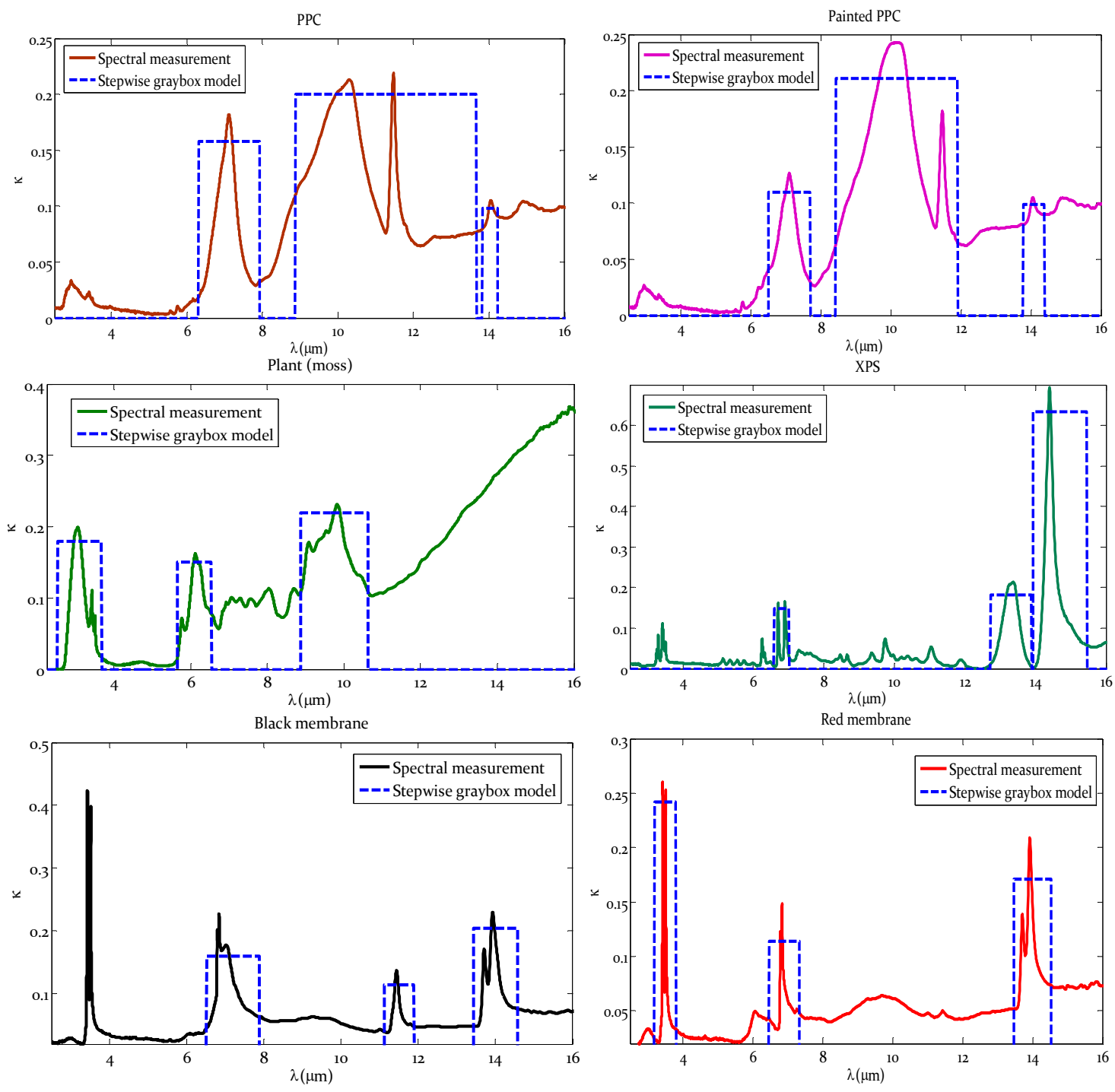

Figure 12. Spectral absorption coefficient of sustainable roof materials. Comparisons of experimental and numerical results, in units of $1 / \mathrm{m}$.

As shown in Figure 12, there is a sharp increase in the spectral absorption coefficient for moss at wavelengths longer than $11 \mu \mathrm{m}$, which could be related to cutin [58]. In plants, for preventing water loss from internal tissues, cuticles are formed as a barrier and can cover the epidermis leaves, fruits, petals of fruits, and non-lignified stems. Cuticles include mostly intracuticular waxes that are embedded in the cutin matrix, and epicuticular waxes that are deposited on the surface [59]. The sharp increase was attributed to the presence of cutin in moss.

\subsection{Numerical Analyses}

\subsubsection{Power of Cooling Calculated for Constant Temperature}

The net radiative cooling power or power of cooling depends on three parameters: (1) The temperature of a surface; (2) the emissivity of a surface; and (3) the inclination of the radiator surface from the zenith. The first and the third properties, are taken as constants in this study. Therefore, the only 
variable that affects the power of cooling is the spectral emissivity of different samples, which is related to the nature of the material [60].

To calculate the power of cooling or net power $\left(P_{\text {net }}\right)$, equations 1 to 9 were solved in MATLAB using the experimental data obtained from the FTIR measurements (Figure 9). $T_{a m b}$ is considered $30{ }^{\circ} \mathrm{C}$ or $303 \mathrm{~K}$, and $\theta=0$. Non-radiative heat transfer coefficient $h_{c}$ is assumed negligible, since it is not related to the radiative performance of these samples. Comparisons of the cooling performance of each sample, are presented in Table 2.

In the first set of comparisons, the results for different samples were considered along with those for the ideal case. What we call as the "ideal sample" is the surface with the most desirable spectral properties. Such a "selective emitter" should have unit emissivity in the 8-13 $\mu \mathrm{m}$ wavelength range, and zero emissivity in other bands. The schematic of the ideal or selective emitter and blackbody emitter, is shown in Figure 13. A blackbody emitter has unity value, for its emissivity at all wavelengths.

Table 2. Comparisons of the cooling characteristics of each surface.

\begin{tabular}{|c|c|c|c|}
\hline $\begin{array}{c}\text { Material } \\
T_{a m b}=303 \mathrm{~K}\end{array}$ & $\begin{array}{c}\text { Net Radiative Power }\left(\mathrm{W} / \mathrm{m}^{2}\right) \\
P_{\text {rad }} \text { at } 273 \mathrm{~K} \\
\end{array}$ & $\begin{array}{c}\text { Net Radiative Power }\left(\mathrm{W} / \mathrm{m}^{2}\right) \\
P_{\text {rad }} \text { at } 283 \mathrm{~K} \\
\end{array}$ & $\begin{array}{c}\text { Net Radiative Power }\left(\mathrm{W} / \mathrm{m}^{2}\right) \\
P_{\text {rad }} \text { at } 293 \mathrm{~K}\end{array}$ \\
\hline PPC & 12.4 & 15.4 & 18.7 \\
\hline Painted PPC & 12.9 & 16.0 & 19.4 \\
\hline Plant or moss & 23.5 & 28.6 & 34.2 \\
\hline Black membrane & 8.2 & 10.4 & 12.7 \\
\hline Red membrane & 7.3 & 9.0 & 11.0 \\
\hline XPS & 6.5 & 8.0 & 9.7 \\
\hline $\begin{array}{c}\text { Selective emitter } \\
\text { (Ideal sample) }\end{array}$ & 47.9 & 60.4 & 74.5 \\
\hline
\end{tabular}

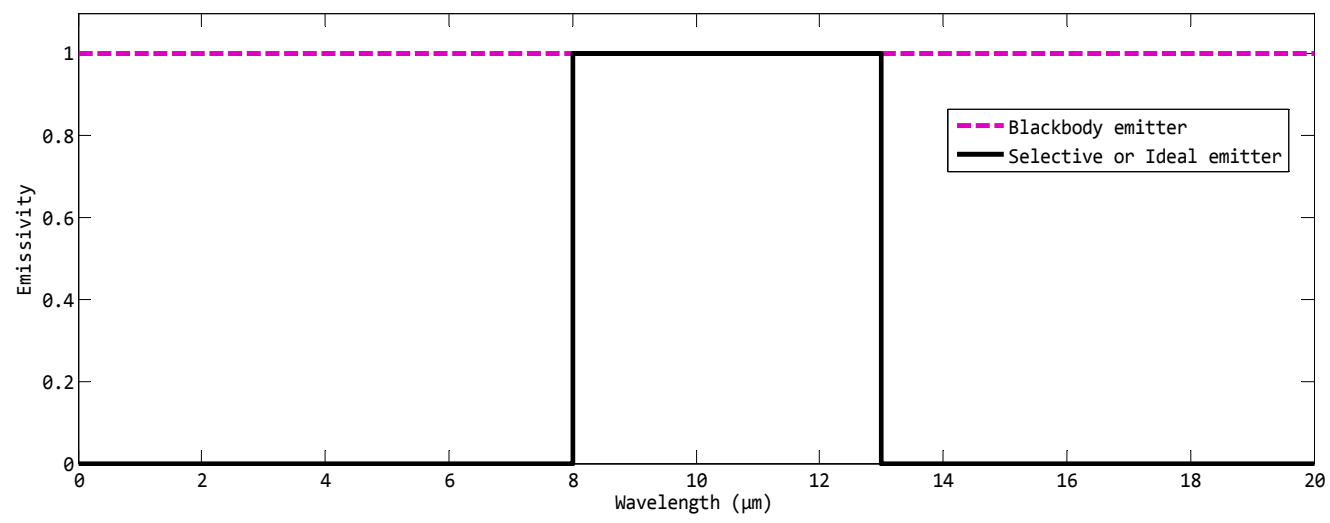

Figure 13. Spectral emissivity of an ideal selective emitter and a blackbody.

Among the samples considered in this study, the moss sample had the highest cooling power of $34.2 \mathrm{~W} / \mathrm{m}^{2}$ at a surface temperature of $293 \mathrm{~K}$ and ambient temperature of $303 \mathrm{~K}$. Under the same conditions, the selective emitter (ideal sample) had cooling power of $74.5 \mathrm{~W} / \mathrm{m}^{2}$. White painted PPC and PPC, had the highest cooling power after the moss sample, with cooling powers of $19.4 \mathrm{~W} / \mathrm{m}^{2}$ and $18.7 \mathrm{~W} / \mathrm{m}^{2}$, respectively. Their values were close to each other and showed that painting a PPC sample does not improve the power of cooling too much. In the remaining samples, the cooling power was lower than those mentioned above.

Silicon oxide, which is essentially glass, is also suggested to be used as a possible radiative cooler; its properties as a selective radiator and corresponding power of cooling were reported [60]. In Table 3, the power of cooling of silicon oxide is compared to the moss sample, which had the highest power of cooling in this study. It was clear that moss could be a better radiative cooler, rather than the silicon oxide, and grows naturally. Moss is a sustainable material, which can be easily used in green-roof applications. 
Table 3. Comparisons of the cooling characteristics of Moss and silicon oxide surfaces.

\begin{tabular}{cc}
\hline Material & Net Radiative Power $\left(\mathrm{W} / \mathrm{m}^{2}\right)$ \\
$\boldsymbol{T}_{\boldsymbol{a m b}}=\mathbf{3 0 3 \mathrm { K }}$ & $\boldsymbol{P}_{\text {rad }}$ at $\mathbf{2 9 3} \mathrm{K}$ \\
\hline Plant or moss & 34.2 \\
Silicon oxide & 27.5 \\
\hline
\end{tabular}

Figure 14 shows the radiative cooling of different samples in the summer, for both daytime and nighttime, corresponding to different surface temperatures. The change in the radiative cooling power of the samples at the ambient temperature of $30{ }^{\circ} \mathrm{C}\left(303 \mathrm{~K}\right.$, at daytime) and $20{ }^{\circ} \mathrm{C}(293 \mathrm{~K}$, at nighttime) were modeled and plotted. These calculations were performed as discussed in Section 2 and were based on the Equations (1)-(9). The ideal composite surface always has the highest cooling power when the ambient temperature is higher than the surface temperature. In that sense, the selective emitter, has the highest power of cooling. Both PPC and white painted PPC showed similar cooling performance, since their spectral emissivities were similar, whilst black membrane, red membrane, and XPS displayed low power of cooling compared to the ideal selective emitter.

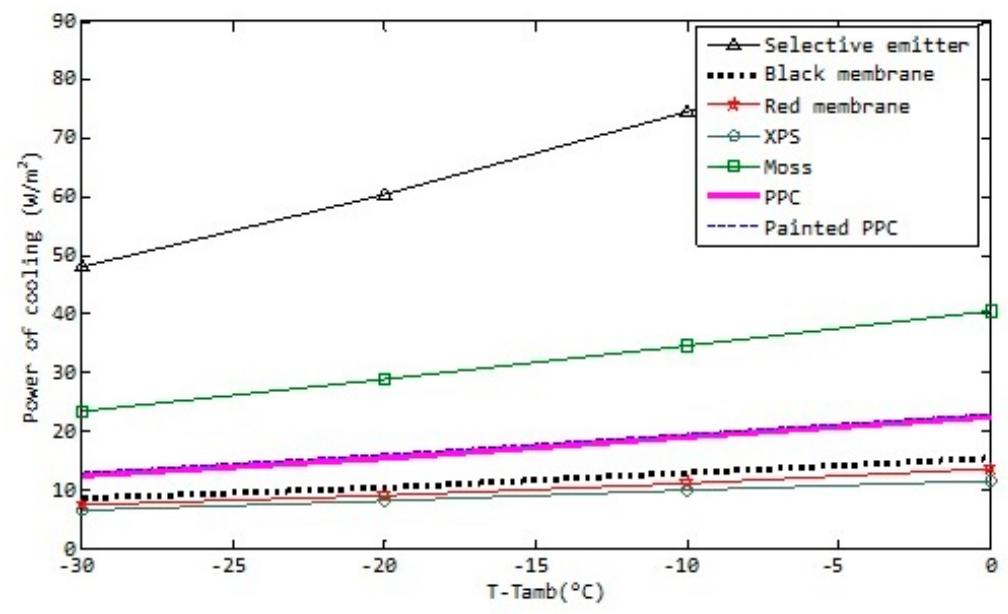

(a)

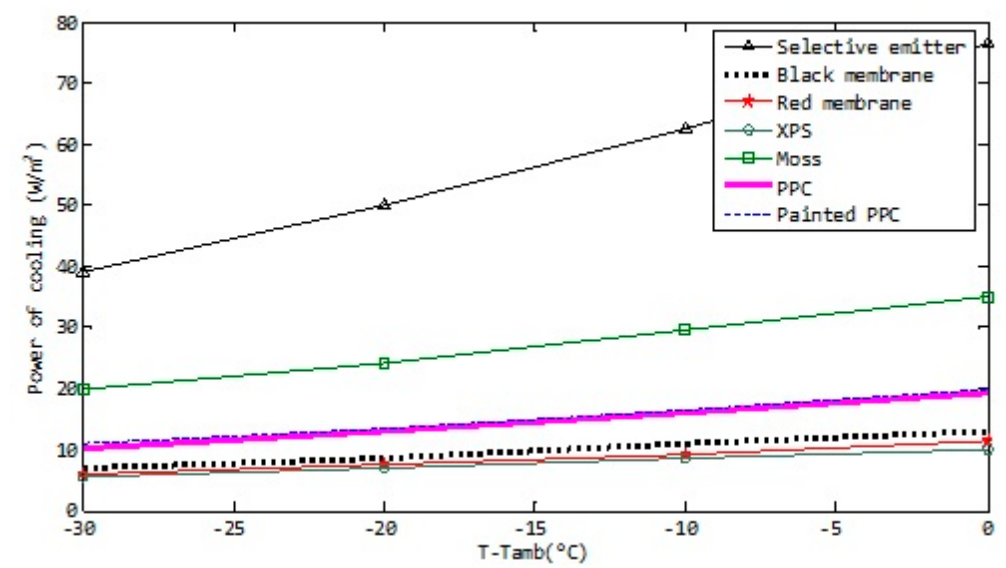

(b)

Figure 14. Change in radiative cooling power of the samples in summer, as a function of surface temperatures, for two different values of ambient temperatures: (a) $30{ }^{\circ} \mathrm{C}$ Daytime; and (b) $20{ }^{\circ} \mathrm{C}$ Nighttime. 
The change in the radiative cooling power of different samples for winter at the ambient temperature of $10{ }^{\circ} \mathrm{C}$ ( $283 \mathrm{~K}$, during daytime) and $0{ }^{\circ} \mathrm{C}(273 \mathrm{~K}$, during nighttime), is shown in Figure 15 (based on Equations (1)-(9) in Section 2). The ideal selective emitter and the moss sample have the highest cooling power. From these results, we could comment that for summer daytime cooling, moss was better than all other samples.

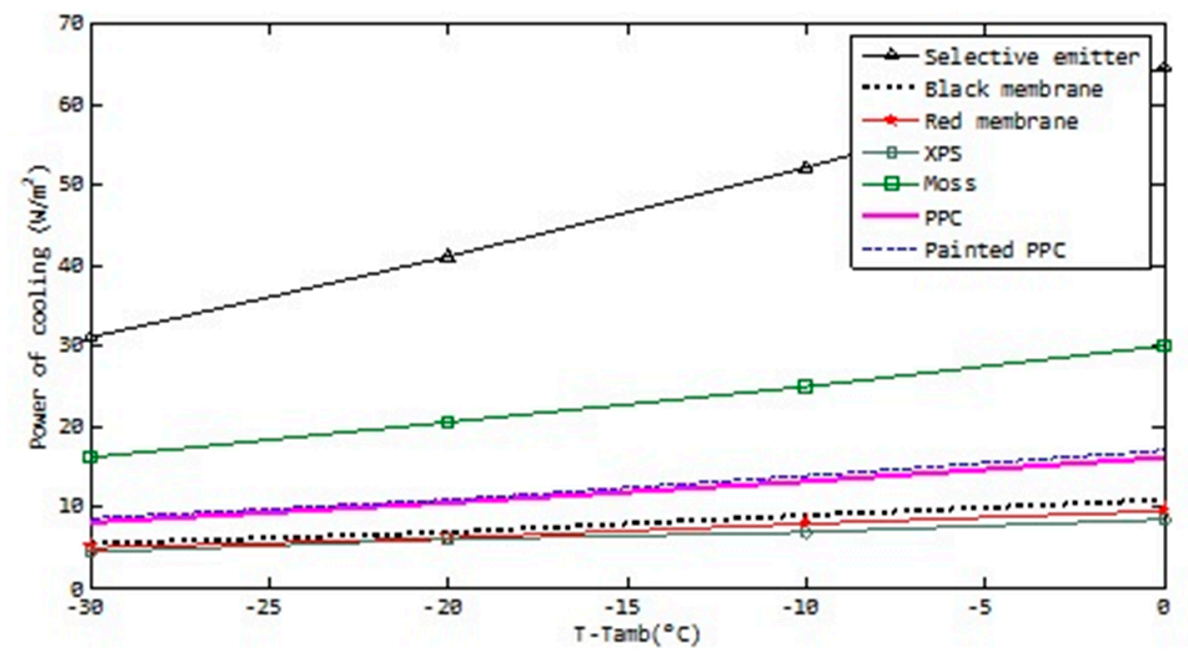

(a)

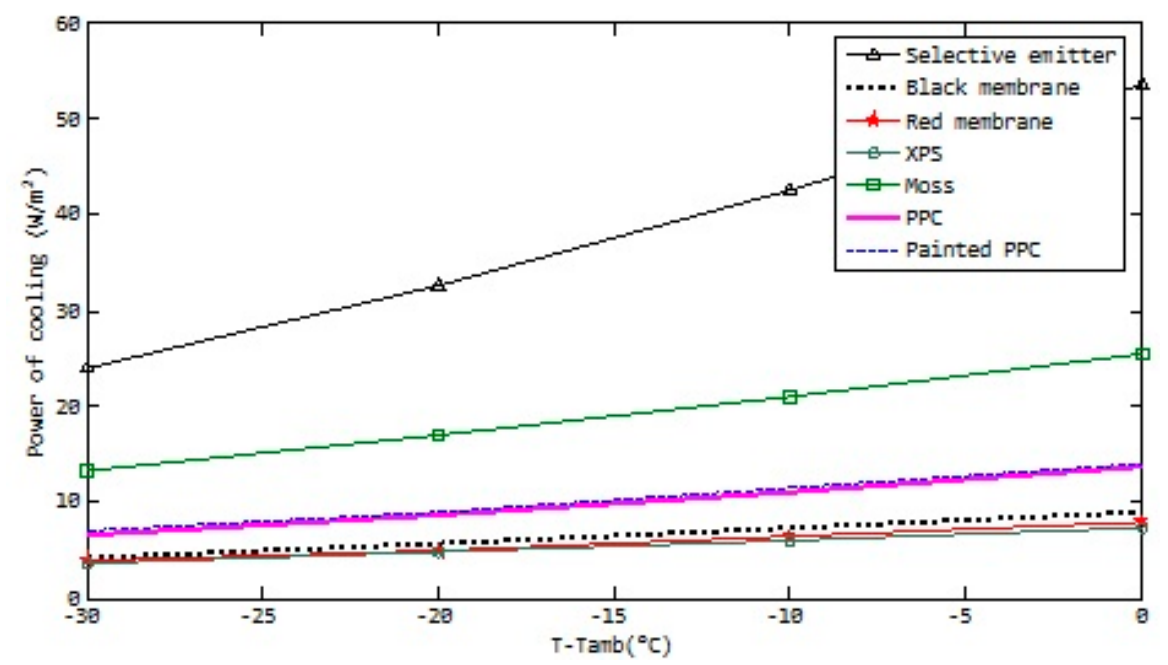

(b)

Figure 15. Change in radiative cooling power of the samples in winter time as a function of surface temperatures, at ambient temperatures of (a) $10{ }^{\circ} \mathrm{C}$ Daytime; and (b) $0{ }^{\circ} \mathrm{C}$ Nighttime.

\subsubsection{Coupled Heat Conduction and Radiation Simulations}

In this section, we discuss the results for a non-gray medium with a temperature gradient in the medium, as discussed in Section 2. This case is closely related to energy transfer through porous structures, such as painted walls or roofs. We omit the effect of convection (wind) for the sake of simplicity, which can be easily added.

Numerical simulations for a non-gray case were performed based on the six different materials. The properties used are outlined in Table 1, based on the parameters listed in Table 4. A stepwise gray model was used the spectrum consisted of three spectral bands (based on [20]). 
Table 4. Summary of the parameters used in the analysis.

\begin{tabular}{ccccc}
\hline$T_{0}$ & $T_{L}$ & $\lambda_{1}$ & $\lambda_{2}$ & $\lambda_{3}$ \\
\hline $293 \mathrm{~K}$ & $300 \mathrm{~K}$ & $2.7 \mu \mathrm{m}$ & $4.3 \mu \mathrm{m}$ & $15 \mu \mathrm{m}$ \\
\hline
\end{tabular}

Optical properties of the materials studied, were not available in the literature. Consequently, their emissivities and absorption coefficients were determined from our own experimental work, as described in Section 4.1.2. In the conduction heat transfer calculations, the thermal conductivities of the samples were needed. These values can be determined from the experimentally measured resistance, R-values. Therefore, we used the Reverse Heat Leak Method (RHLM), which was discussed in our previous papers $[27,28]$. They are listed in Table 5.

Table 5. Thermal conductivities of the materials [27,28].

\begin{tabular}{ccc}
\hline Name & $\boldsymbol{R}$ Value $\left(\mathbf{K} \cdot \mathbf{m}^{\mathbf{2}} / \mathbf{W}\right)$ & $\boldsymbol{k} \mathbf{( W / m} \cdot \mathbf{K})$ \\
\hline PPC & 0.222 & 2.25 \\
Painted PPC & 0.282 & 1.77 \\
Plant or moss & 0.261 & 1.91 \\
XPS & 0.826 & 0.96 \\
Black membrane & 0.252 & 1.98 \\
Red membrane & 0.077 & 6.49 \\
\hline
\end{tabular}

The temperature profiles for 1D media were determined from a coupled conduction and radiation analysis, as discussed before. These profiles depicted a non-linear behavior because of radiative absorption within the medium [19]. The nonlinear temperature profile is due to the volumetric absorption of incident radiation by the slab.

Figure 16 shows the temperature profiles for a gray case, which is plotted to evaluate the validity of the codes. Figure 17 shows the temperature profiles obtained from simulations for different materials. The results showed the nonlinear steady-state temperature profile for homogeneous media, where the conduction to radiation parameter was lower than one, as already explained in References $[1,22,55,61]$.

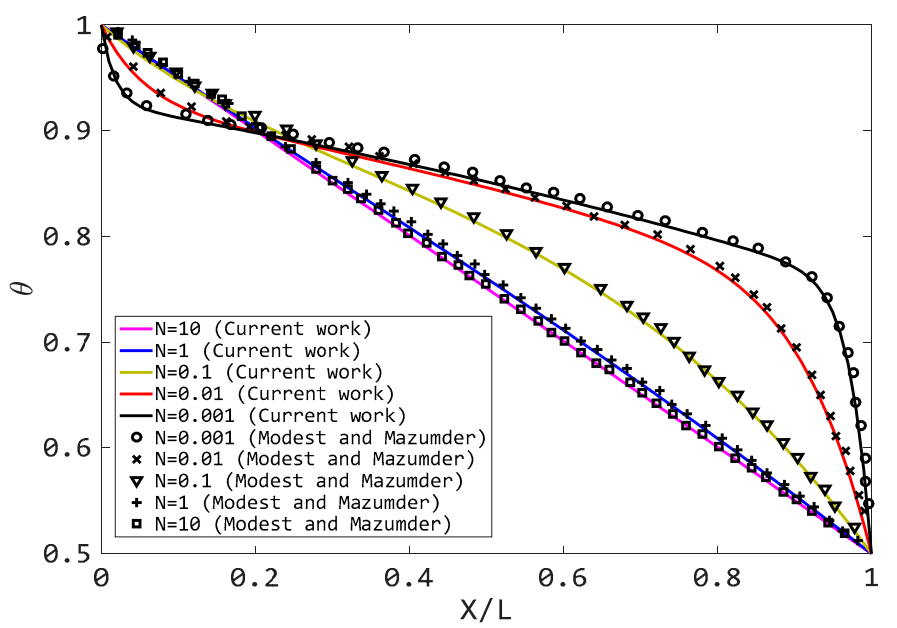

Figure 16. Validation of the numerical analysis for non-dimensional temperature profiles for combined radiation and conduction transfer in a gray slab (comparisons are made against Modest book [22] and Mazumder paper [20]).

In the next set of simulations given below, the walls were considered to be at the same temperature. By doing so, we focused only on the effect of material emissivity. The predicted temperature profiles 
are shown in Figure 17 in non-dimensional fashion, although they correspond to a wall thickness $50 \mathrm{~cm}$. It should be mentioned that this physical size was just an assumption and the code could be applied for any physical sizes.

It can be seen from Figures 16 and 17 that the higher temperatures (non-dimensional temperature $\theta$ near 1) are in the near-wall region. In this region, which was the surface of the roof for our model, the radiation mechanism was more significant, as radiation is a surface phenomenon. As mentioned in Reference [62], when the boundaries are opaque, the temperature peaks can only appear at the heated surface, as the radiative energy might not transfer to the inside of the medium directly but can only heat the surface. Consequently, the energy is transferred inside from the heated surface.

In Figure 17, from the surface through the sample, red membrane is on the top with high non-dimensional temperature, as it has the highest conductivity among all samples. Therefore, it shows that heat conduction was dominant in this sample. On the other hand, XPS and moss had the lowest non-dimensional temperature in comparison with other samples. XPS as mentioned before, is a good insulator, with the lowest conductivity, and its spectral emissivity is also low in mentioned bands. Moss sample had average conductivity and high spectral emissivity. Radiation transfer was more dominant in moss, rather than conduction, and it has a higher potential to be a radiative cooler.

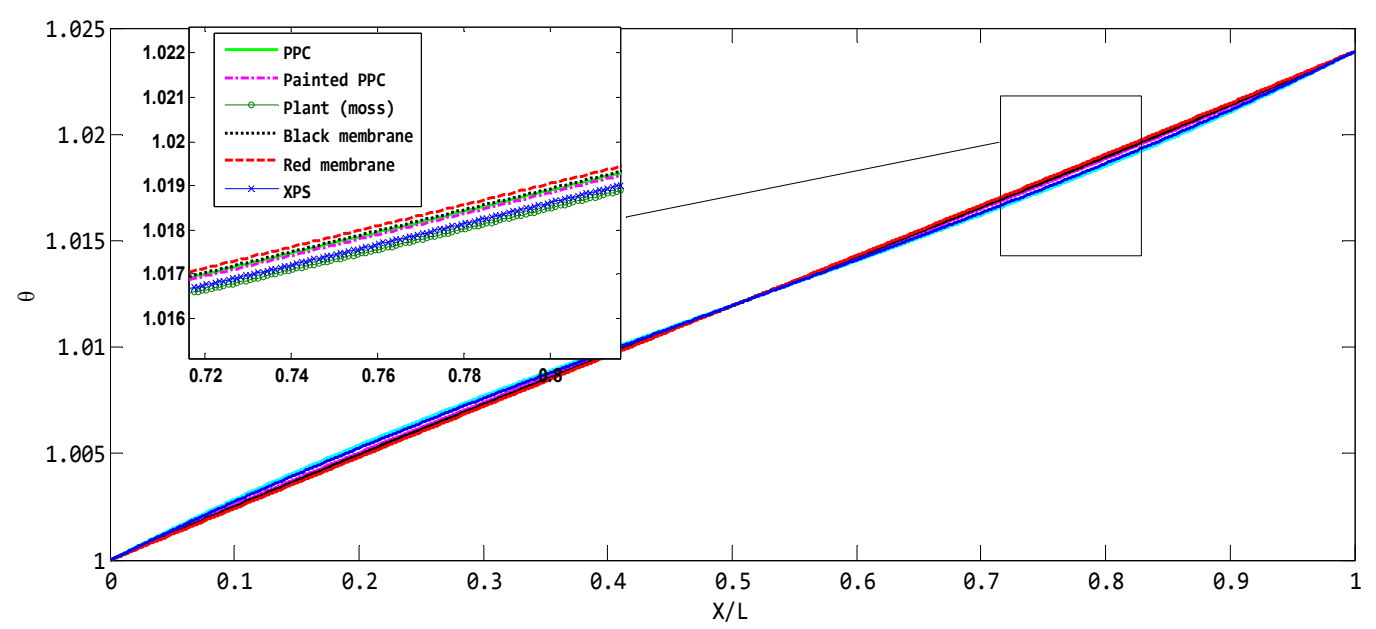

(a)

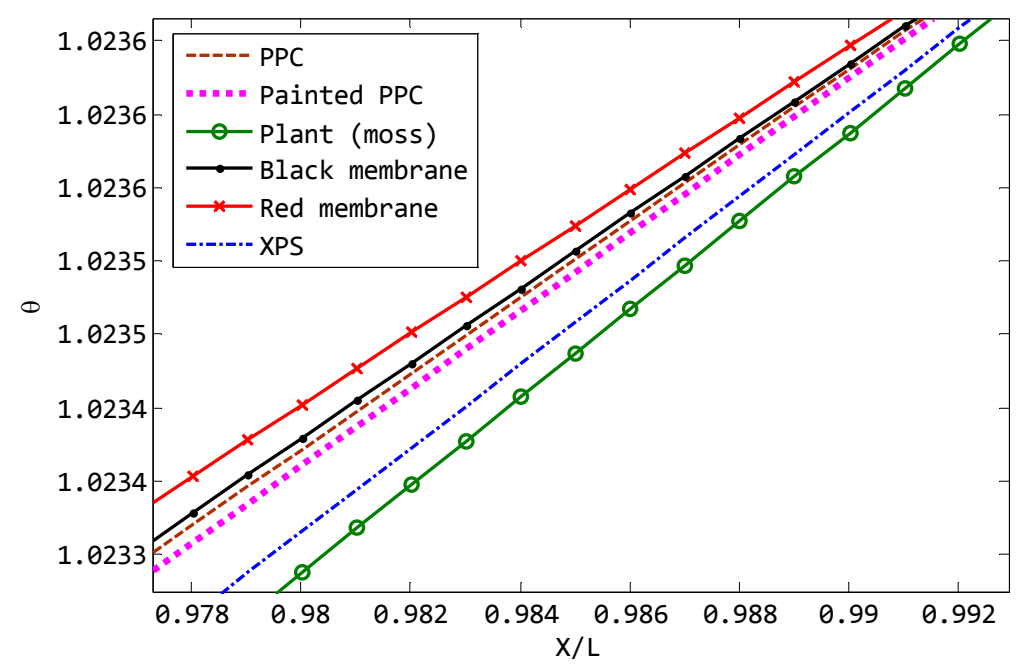

(b)

Figure 17. (a) Temperature profile using the non-gray formulations for different roof materials; and (b) Right part zoomed. 


\section{Discussions and Conclusions}

In this study, several sustainable materials were analyzed to explore their radiative heating and cooling potentials. These materials have several environmental benefits, such as being non-toxic, reusable, and renewable; and they can enhance the cooling performance of the roofs and walls of buildings in an inexpensive way. When choosing the materials for this study, our emphasis was on the following criteria:

1. Materials which have high spectral emissivity in both solar band $(0.2-2 \mu \mathrm{m})$ and atmospheric window $(8-13 \mu \mathrm{m})$ were considered; these materials are good candidates as solar collectors at daytime, and solar emitters or radiator coolers at night time.

2. Materials which have high spectral emissivity in the atmospheric window $(8-13 \mu \mathrm{m})$ and low spectral emissivity outside of this window were considered; radiative cooling can be achieved on the surface of these materials, and they are good candidates as radiative coolers at daytime.

3. Materials which have high spectral emissivity at solar band and low spectral emissivity in other bands were considered; as they are good candidates for solar energy absorption.

Based on these criteria, we considered red membrane, black membrane, XPS, PPC, painted PPC, and moss. These materials were available and abundant in Turkey, where the study was conducted. Among these, moss, PPC, and painted PPC could be considered as radiative coolers, and black membrane would be a solar absorber.

As the optical properties of the materials were not available in the literature, as a first step, the experimental analyses for all samples were carried out and their spectral emissivity and reflectivity were measured using an FTIR spectrometer and UV-Visible spectrophotometer. These results were later converted to spectral absorption coefficient data. In numerical analysis, the power of cooling for the opaque samples at constant temperature was calculated. Results were compared against an ideal selective emitter. The best sample for potential radiative cooling purposes was deemed to be moss, whose power of cooling was even higher than Silicon oxide samples. Power of cooling was also calculated for all samples, for summer and winter daytime and nighttime performances, and then they were compared against those of a selective ideal emitter.

Radiation transfer is usually a volumetric phenomenon, as such a coupled conduction and radiation analysis was also carried out for semi-transparent materials. A numerical model was developed and solved with MATLAB, using the experimental spectral absorption coefficient and thermal conductivity data obtained from our experiments. In order to validate the codes, the coupled conduction and radiation problem was first solved for a gray case, and then compared against the data available in the literature. These coupled analyses were then extended to non-gray materials using stepwise gray box models.

Among all materials considered, moss was deemed to be the best candidate as a sustainable material to be used as a radiative cooler for outside surfaces of buildings. However, its conductivity was higher than a sample like XPS, for being a good insulator. Therefore, moss should be grown on a better insulator surface to have the highest possible benefit from it. A summary of the findings of the present study for different materials considered, is presented in Table 6 to help the reader to make a quick comparison between them. 
Table 6. Cooling behavior of materials for building applications during winter and summer months in Mediterranean regions.

\begin{tabular}{cccc}
\hline Material & $\begin{array}{c}\text { Potential as a Solar } \\
\text { Absorber }\end{array}$ & $\begin{array}{c}\text { Potential as a Day Time } \\
\text { Radiative Cooler }\end{array}$ & $\begin{array}{c}\text { Potential as a Night } \\
\text { Time Radiative Cooler }\end{array}$ \\
\hline PPC & Weak & Good & Good \\
Painted PPC & Weak & Good & Good \\
Plant or moss & Weak & Good & Good \\
Black membrane & Very good & Weak & Weak \\
Red membrane & Good & Weak & Weak \\
XPS & Weak & Very weak & Very weak \\
\hline
\end{tabular}

Author Contributions: Conceptualization, R.F. and M.P.M.; Methodology, R.F.; Software, R.F.; Validation, R.F., M.P.M.; Formal Analysis, R.F.; Investigation, R.F. and M.P.M.; Data Curation, R.F. and M.P.M.; Writing-Original Draft Preparation, R.F.; Writing-Review \& Editing, R.F. and M.P.M.; Supervision, M.P.M.; Project Administration, M.P.M.

Funding: This research has not received any external funding.

Acknowledgments: This work is supported by the Center for Energy, Environment and Economy (CEEE) at Ozyegin University, Istanbul, Turkey. FTIR and UV-Visible spectral experimental measurements were carried out at Sabanci University (SU) in Istanbul, Turkey. The support of C. Ow-Yang in Smart Materials Characterization Laboratory-L021 at SUNUM Facilities of SU is gratefully acknowledged.

Conflicts of Interest: The authors declare no conflict of interest.

\section{Nomenclature}

\begin{tabular}{|c|c|}
\hline$A$ & Area $\left(m^{2}\right)$ \\
\hline$C_{p}$ & Specific heat capacity $(\mathrm{J} / \mathrm{kg} / \mathrm{K})$ \\
\hline$E_{b \lambda}$ & Blackbody emissive power $\left(\mathrm{W} / \mathrm{m}^{3}\right)$ \\
\hline$G_{\lambda}$ & Spectral incident radiation $\left(\mathrm{W} / \mathrm{m}^{3}\right)$ \\
\hline$h_{c}$ & Non-radiative heat exchange coefficient \\
\hline$I_{A M 1.5}$ & The solar illumination \\
\hline$I_{B B}$ & Spectral radiance of a blackbody at temperature $\mathrm{T}$ \\
\hline$K_{B}$ & Boltzmann constant $(\mathrm{J} / \mathrm{K})$ \\
\hline$q^{c}$ & Conductive heat flux $\left(\mathrm{W} / \mathrm{m}^{2}\right)$ \\
\hline$q^{R}$ & Radiative heat flux $\left(\mathrm{W} / \mathrm{m}^{2}\right)$ \\
\hline$\dot{S}_{T}$ & Source term for energy equation $\left(\mathrm{W} / \mathrm{m}^{3}\right)$ \\
\hline $\mathrm{T}$ & Temperature (K) \\
\hline $\mathrm{T}_{\mathrm{amb}}$ & Ambient temperature $(\mathrm{K})$ \\
\hline$t(\lambda)$ & The atmospheric transmittance in the zenith direction \\
\hline $\mathrm{U}$ & Velocity vector $(\mathrm{m} / \mathrm{s})$ \\
\hline \multicolumn{2}{|c|}{ Greek symbol } \\
\hline$\varepsilon$ & Emissivity \\
\hline$\varepsilon_{a t m}$ & The angle-dependent emissivity of the atmosphere \\
\hline$\varepsilon_{\lambda}$ & Spectral emissivity \\
\hline$\kappa_{\lambda}$ & Spectral absorption coefficient $\left(\mathrm{m}^{-1}\right)$ \\
\hline$\kappa_{B}$ & Absorption coefficient of background $\left(\mathrm{m}^{-1}\right)$ \\
\hline$\lambda$ & Wavelength $(\mu \mathrm{m})$ \\
\hline$\lambda_{k, u}$ & Upper wavelength of kth spectral box (m) \\
\hline$\lambda_{k, l}$ & lower wavelength of kth spectral box (m) \\
\hline$\eta$ & Wavenumber $\left(\mathrm{cm}^{-1}\right)$ \\
\hline$\sigma$ & Stefan-Boltzmann constant $\left(5.67 \times 10-8 \mathrm{~W} \cdot \mathrm{m}^{-2} \cdot \mathrm{K}^{-4}\right)$ \\
\hline$\sigma_{s \lambda}$ & Spectral scattering coefficient $\left(\mathrm{m}^{-1}\right)$ \\
\hline$\Omega$ & Solid angle (sr) \\
\hline$\theta$ & Polar angle and dimensionless temperature \\
\hline$\rho$ & Density $\left(\mathrm{Kg} / \mathrm{m}^{3}\right)$ \\
\hline
\end{tabular}




\section{References}

1. Howell, J.R.; Menguc, M.P.; Siegel, R. Thermal Radiation Heat Transfer, 6th ed.; CRC Press: Boca Raton, FL, USA; Taylor \& Francis: Didcot, UK; Abingdon, UK, 2016.

2. Nilsson, T.M.J.; Niklasson, G.A.; Granqvist, C.G. A solar reflecting material for radiative cooling applications: ZnS pigmented polyethylene. Sol. Energy Mater. Sol. Cells 1992, 28, 175-193. [CrossRef]

3. Zhu, L.; Raman, A.; Fan, S. Color-preserving daytime radiative cooling. Appl. Phys. Lett. 2013, 103, 223902. [CrossRef]

4. Dunkle, R.V. Thermal Radiation Characteristics of Surfaces. In Theory and Fundamental Research in Heat Transfer; Pergamon Press Ltd.: Oxford, UK, 1963; pp. 1-31.

5. Reed, B.D.; Biglow, J.; Schneider, S. Engineering Issues of Iridium Coated Rhenium Rockets. Mater. Manuf. Process 1998, 13, 757-771. [CrossRef]

6. Henninger, J.H. Solar Absorptance and Thermal Emittance of Some Common Spacecreaft Thermal Control Coatings; National Aeronautics and Space Administration: Washington, DC, USA, 1984; Volume 1121.

7. Hall, D.F.; Fote, A. Thermal control coatings performance at near geosynchoronous altitude. J. Thermophys. Heat Transf. 1992, 6, 665-671. [CrossRef]

8. Swirnow, W. Properties of Emissive Materials. Infrared Imaging Services, LLC. Available online: https: / / www.irinfo.org/03-01-2014-swirnow / (accessed on 3 January 2014).

9. Gonome, H.; Baneshi, M.; Okajima, J.; Komiya, A.; Maruyama, S. Controlling the radiative properties of cool black-color coatings pigmented with $\mathrm{CuO}$ submicron particles. J. Quant. Spectrosc. Radiat. Transf. 2014, 132, 90-98. [CrossRef]

10. Rose, M.F.; Adair, P.; Schroeder, K. Selective emitters for thermophotovoltaic power systems for use in aerospace applications. J. Propuls. Power 1996, 12, 83-88. [CrossRef]

11. Wijewardane, S.; Goswami, D.Y. A review on surface control of thermal radiation by paints and coatings for new energy applications. Renew. Sustain. Energy Rev. 2012, 16, 1863-1873. [CrossRef]

12. Licciulli, A.; Diso, D.; Torsello, G.; Maffezzoli, A.; Lomascolo, M.; Mazzer, M. The challenge of high-performance selective emitters for thermophotovoltaic. Semicond. Sci. Technol. 2003, 18, S174. [CrossRef]

13. Torsello, G.; Lomascolo, M.; Licciulli, A.; Diso, D.; Tundo, S.; Mazzer, M. The origin of highly efficient selective emission in rare-earth oxides for thermophotovoltaic applications. Nat. Mater. 2004, 3, 632-637. [CrossRef] [PubMed]

14. Sentenac, J.; Greffet, A. Design of surface microrelief with selective radiative properties. Int. J. Heat Mass Transf. 1994, 37, 553-558. [CrossRef]

15. Greffet, J.J.; Henkel, C. Coherent thermal radiation. Contemp. Phys. 2007, 48, 183-194. [CrossRef]

16. Chen, S.; Wang, H.; Zhou, J.; Fang, L.; Lu, C.; Xu, Z. Photoresponsive hydrogels with high wavelength selectivity for near-infrared light. Mater. Lett. 2018, 219, 163-165. [CrossRef]

17. Shankar, R.; Florjanczyk, M.; Hall, T.J.; Vukovic, A.; Hua, H. Multi-degree ROADM based on wavelength selective switches: Architectures and scalability. Opt. Commun. 2007, 279, 94-100. [CrossRef]

18. Center for Sustainable Materials, Sustainability and Sustainable Materials; Rutgers University: Camden, NJ, USA, 2010.

19. Ferkl, P.; Pokorný, R.; Bobák, M.; Kosek, J. Heat transfer in one-dimensional micro- and nano-cellular foams. Chem. Eng. Sci. 2013, 97, 50-58. [CrossRef]

20. Mazumder, S. A new numerical procedure for coupling radiation in participating media with other modes of heat transfer. J. Heat Transf. 2005, 127, 1037-1045. [CrossRef]

21. Lord, S.D. A New Software Tool for Computing Earth's Atmospheric Transmission of Near-and Far-Infrared Radiation; NASA Ames Research Center: Moffett Field, CA, USA, 1992.

22. Modest, M.F. Radiative Heat Transfer, 3rd ed.; Academic Press: Cambridge, MA, USA, 2013.

23. Whitaker, S. Fundamental Principles of Heat Transfer; Pergamon Press: Oxford, UK, 1977.

24. Viskanta, R.; Menguc, M.P. Radiation heat transfer in combustion systems. Prog. Energy Combust. Sci. 1987, 13, 97-160. [CrossRef]

25. Modest, M.F.; Sikka, K.K. The stepwise gray P-1 approximation for multi-dimensional radiative transfer in molecular gas particulate mixtures. J. Quant. Spectrosc. Radiat. Transf. 1992, 48, 159-168. [CrossRef]

26. Family, R.; Menguc, M.P. Materials for Radiative Cooling: A review. Procedia Environ. Sci. 2017, 38, 752-759. [CrossRef] 
27. Celik, S.; Family, R.; Menguc, M.P. Analysis of perlite and pumice based building insulation materials. J. Build. Eng. 2016, 6, 105-111. [CrossRef]

28. Celik, S.; Family, R.; Menguc, M.P. Thermal Evaluation of Perlite and Pumice Based Building Insulation Materials Using Reverese Heat Leak Method. In Proceedings of the 1st Thermal and Fluid Engineering Summer Conference, New York, NY, USA, 9-12 August 2015.

29. Saeli, M.; Piccirillo, C.; Tobaldi, D.M.; Binions, R.; Castro, P.L.M.; Pullar, R.C. A sustainable replacement for $\mathrm{TiO}_{2}$ in photocatalyst construction materials: Hydroxyapatite-based photocatalytic additives, made from the valorisation of food wastes of marine origin. J. Clean. Prod. 2018, 193, 115-127. [CrossRef]

30. Fic, K.; Platek, A.; Piwek, J.; Frackowia, E. Sustainable materials for electrochemical capacitors. Mater. Today 2018, 21, 437-454. [CrossRef]

31. Wunsch, J.R. Polystyrene: Synthesis, Production and Applications; iSmithers Rapra Publication: Shawbury, Shrewsbury, Shropshire, UK, 2000.

32. GmbH, J. What Is XPS (Extruded Polystyrene Foam). Foam Technology. 2001. Available online: http: / /iwi-gmbh.com/iwi/pdf/IWI_XPS_en.pdf (accessed on 1 October 2001).

33. Ravishankar, P.S. Treatise on EPDM. Rubber Chem. Technol. 2012, 85, 327-349. [CrossRef]

34. Chen, J.; Huang, W.; Jiang, S.B.; Li, X.Y.; An, Y.; Li, C.; Gao, X.L.; Chen, H.B. Flame-retardant EPDM compounds containing phenanthrene to enhance radiation resistance. Radiat. Phys. Chem. 2017, 130, 400-405. [CrossRef]

35. Kultur, S.; Turkeri, N. Assessment of long term solar reflectance performance of roof coverings measured in laboratory and in field. Build. Environ. 2012, 48, 164-172. [CrossRef]

36. Brennan, M.P.; Abramase, A.L.; Andrews, R.W.; Pearce, J.M. Solar Energy Materials \& Solar Cells Effects of spectral albedo on solar photovoltaic devices. Sol. Energy Mater. Sol. Cells 2014, 124, 111-116.

37. Pumping, M.C. Foam Pouring Concrete: Making High Performance Homes with Sustainability. 2016. Available online: http://www.mapleconcretepumping.ca/foam-pouring-concrete-making-highperformance-homes-withsustainability/ (accessed on 15 November 2016).

38. Vaou, V.; Panias, D. Thermal insulating foamy geopolymers from perlite. Miner. Eng. 2010, 23, $1146-1151$. [CrossRef]

39. Benk, A.; Coban, A. Possibility of producing lightweight, heat insulating bricks from pumice and $\mathrm{H}_{3} \mathrm{PO}_{4}$-or $\mathrm{NH}_{4} \mathrm{NO}_{3}$-hardened molasses binder. Ceram. Int. 2012, 38, 2283-2293. [CrossRef]

40. Gündüz, L. The effects of pumice aggregate/cement ratios on the low-strength concrete properties. Constr. Build. Mater. 2008, 22, 721-728. [CrossRef]

41. Girgin, I. Lightweight, Heat Insulating, High Mechanical Strength Shaped Product and Method of Producing the Same. U.S. Patent 7,354,542, 8 April 2008.

42. Wattanavatee, K.; Krmar, M.; Bhongsuwan, T. A survey of natural terrestrial and airborne radionuclides in moss samples from the peninsular Thailand. J. Environ. Radioact. 2017, 177, 113-127. [CrossRef] [PubMed]

43. Sun, Z.; Hong, L.; Jingmiao, L.; Guoping, S. Estimation of photosynthetically active radiation using solar radiation in the UV-visible spectral band. Sol. Energy 2017, 153, 611-622. [CrossRef]

44. Griffiths, P.R.; De Haseth, J.A.; Winefordner, J.D. Fourier Transform Infrared Spectrometry, 2nd ed.; Wiley: Hoboken, NJ, USA, 2007.

45. Elkhoshkhany, N.; Khatab, M.A.; Kabary, M.A. Thermal, FTIR and UV spectral studies on tellurite glasses doped with cerium oxide. Ceram. Int. 2018, 44, 2789-2796. [CrossRef]

46. Mauricio-Sánchez, R.A.; Salazar, R.; Luna-Bárcenas, J.G.; Mendoza-Galván, A. FTIR spectroscopy studies on the spontaneous neutralization of chitosan acetate films by moisture conditioning. Vib. Spectrosc. 2018, 94, 1-6. [CrossRef]

47. Soderberg, T. Ultraviolet and Visible Spectroscopy. Libretexts Libraries, Section 4.4, 2017. Available online: https://chem.libretexts.org/Textbook_Maps/Organic_Chemistry/Book\%3A_Organic_Chemistry_ with_a_Biological_Emphasis_\%28Soderberg\%29/Chapter_04\%3A_Structure_Determination_I/4.4\%3A_ Ultraviolet_and_visible_spectroscopy (accessed on 11 April 2017).

48. Khandpur, R.S. Handbook of Analytical Instruments, 3rd ed.; Tata McGraw-Hill: New York, NY, USA, 1989.

49. Hu, M.; Pei, G.; Li, L.; Zheng, R.; Li, J.; Ji, J. Theoretical and Experimental Study of Spectral Selectivity Surface for Both Solar Heating and Radiative Cooling. Int. J. Photoenergy 2015, 2015. [CrossRef]

50. Hu, M.; Pei, G.; Wang, Q.; Li, J.; Wang, Y.; Ji, J. Field test and preliminary analysis of a combined diurnal solar heating and nocturnal radiative cooling system. Appl. Energy 2016, 179, 899-908. [CrossRef] 
51. Mavengere, S.; Kim, J.S. UV-visible light photocatalytic properties of $\mathrm{NaYF}_{4}:(\mathrm{Gd}, \mathrm{Si}) / \mathrm{TiO}_{2}$ composites. Appl. Surf. Sci. 2018, 444, 491-496. [CrossRef]

52. Liu, T.; Chn, Z.; Liu, H.; Zhang, Z. FTIR spectral imaging enhancement algorithm for face recognition in the intelligent learning environment. Infrared Phys. Technol. 2018, 93, 213-222. [CrossRef]

53. Vasylieva, A.; Doroshenko, I.; Vaskivskyi, Y.; Chernolevska, Y.; Pogorelov, V. FTIR study of condensed water structure. J. Mol. Struct. 2018, 1167, 232-238. [CrossRef]

54. Ravindra, N.M.; Ganapathy, P.; Choi, J. Energy gap-refractive index relations in semiconductorsAn overview. Infrared Phys. Technol. 2007, 50, 21-29. [CrossRef]

55. Menguc, M.P. Heat Transfer in a Radiating Laminar Flow between Parallel Plates. Master's Thesis, Middle East Technical University, Ankara, Turkey, 1980.

56. Cheong, J.S.; Baharuddin, A.N.A.P.; Ng, J.S.; Krysa, A.B.; David, J.P.R. Absorption coefficients in AlGaInP lattice-matched to GaAs. Sol. Energy Mater. Sol. Cells 2017, 164, 28-31. [CrossRef]

57. Proctor, C.; Lu, B.; He, Y. Remote Sensing of Environment Determining the absorption coef fi cients of decay pigments in decomposing monocots. Remote Sens. Environ. 2017, 199, 137-153. [CrossRef]

58. Ribeiro da Luz, B.; Crowley, J.K. Spectral reflectance and emissivity features of broad leaf plants: Prospects for remote sensing in the thermal infrared $(8.0-14.0 \mu \mathrm{m})$. Remote Sens. Environ. 2007, 109, 393-405. [CrossRef]

59. Hernández Velasco, B.L.; Arrieta-Baez, D.; Cortez Sotelo, P.I.; Méndez-Méndez, J.V.; Berdeja Martínez, B.M.; Gómez-Patiño, M.B. Comparative studies of cutins from lime (Citrus aurantifolia) and grapefruit (Citrus paradisi) after TFA hydrolysis. Phytochemistry 2017, 144, 78-86. [CrossRef] [PubMed]

60. Bathgate, S.N.; Bosi, S.G. A robust convection cover material for selective radiative cooling applications. Sol. Energy Mater. Sol. Cells 2011, 95, 2778-2785. [CrossRef]

61. Menguc, M.P.; Yener, Y.; Ozisik, M.N. Interaction of Radiation and Convection in Thermally Developing Laminar Flow in a Parallel-Plate Channel. ASME Paper No: 83-HT-035. In Proceedings of the ASME National Heat Transfer Conference, Seattle, WA, USA, 24-28 July 1983.

62. Wang, P.Y.; Tan, H.P.; Liu, L.H.; Tong, T.Y. Coupled radiation and conduction in a scattering composite layer with coatings. J. Thermophys. Heat Transf. 2000, 14, 512-522. [CrossRef]

(C) 2018 by the authors. Licensee MDPI, Basel, Switzerland. This article is an open access article distributed under the terms and conditions of the Creative Commons Attribution (CC BY) license (http:/ / creativecommons.org/licenses/by/4.0/). 